\title{
A Theory of Outsourced Fundraising: Why Dollars Turn into "Pennies for Charity"
}

\author{
Zdravko \\ Paskalev
}

Duke University
Huseyin

Yildirim

Duke University

\section{December 6, 2014}

ERID Working Paper Number 189

This paper can be downloaded without charge from the Social

Science Research Network Electronic Paper Collection:

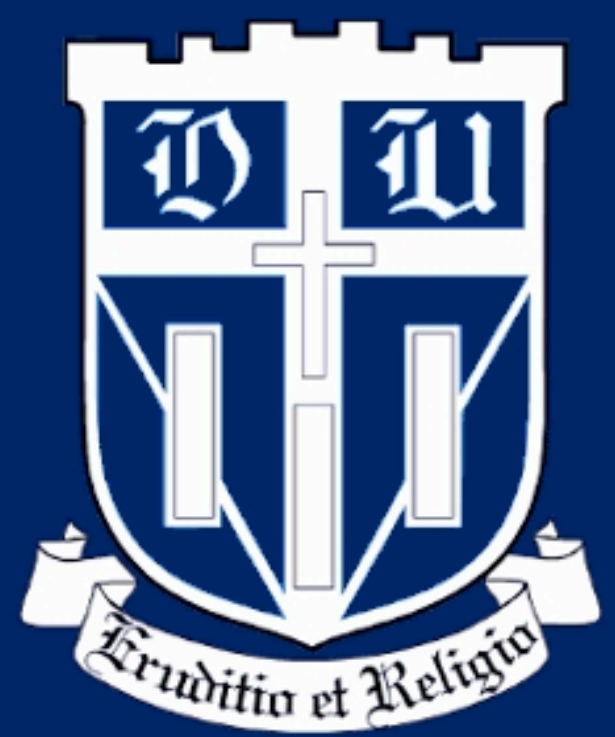




\title{
A Theory of Outsourced Fundraising: Why Dollars Turn into "Pennies for Charity"*
}

\author{
Zdravko Paskalev \\ Department of Economics \\ Duke University \\ Box 90097 \\ Durham, NC 27708 \\ E-mail: zdravko.paskalev@duke.edu
}

\author{
Huseyin Yildirim \\ Department of Economics \\ Duke University \\ Box 90097 \\ Durham, NC 27708 \\ E-mail: yildirh@econ.duke.edu
}

December 6, 2014

\begin{abstract}
Charities frequently rely on professional solicitors whose commissions exceed half of total donations. To understand this practice, we propose a principal-agent model in which the charity optimally offers a higher commission to a more "efficient" solicitor, raising the price of giving significantly. Outsourcing is, therefore, profitable for the charity only if giving is very price-inelastic. This, however, clashes with empirical evidence. We show that paid solicitations can benefit the charity if: (1) donors are unaware; (2) donors have intense "warm-glow" preferences; or (3) the charity worries mostly about watchdog ratings. We argue that informing the public of the mere existence of paid solicitations may be the most effective policy available.
\end{abstract}

Keywords: fund-raising, solicitation, outsourcing, charitable giving.

JEL Classification: H4, L3, L5

\section{Introduction}

Fundraising is essential to most charities - but it is costly. A $25-35 \%$ cost-to-donation ratio is considered reasonable by leading experts (Kelly, 1998; Greenfield, 2002) and watchdog groups such as Charity Navigator and CharityWatch. This benchmark is, however, significantly exceeded by those charities that rely on professional fundraisers. ${ }^{1}$ According to the "Pennies for Charity" report of the New York Attorney General, charities regularly paid

\footnotetext{
*We thank seminar participants at Duke, Tulane, and UCSD for comments. All errors are ours.

1 "Professional fundraiser" is a legislated term often used for a third-party whose services are contracted for. This term excludes employees of the charitable organization (Hopkins, 2009).
} 
more than half of the solicited donations to telemarketing companies; see Figure $1 .^{2,3}$

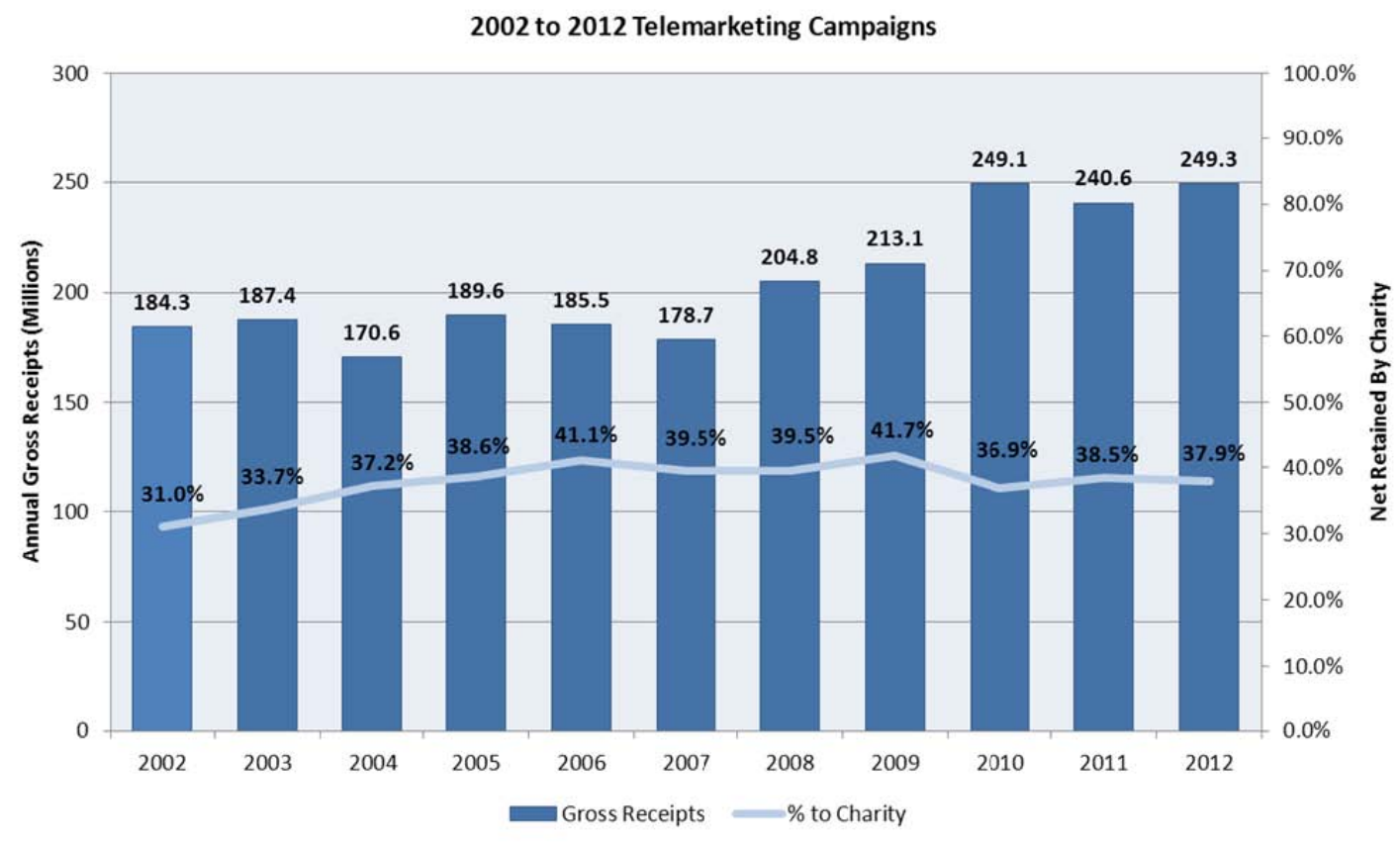

Figure 1: Telemarketing in New York (Source: 2013 Pennies for Charity)

Paid solicitors have also attracted media scrutiny. A 2012 story by the Bloomberg Markets magazine revealed that from 2007 to 2010, a major telemarketing company kept 52\% of $\$ 424.5$ million raised on behalf of 30 nonprofits, including American Cancer Society and March of Dimes - two of the largest in the U.S. ${ }^{4}$ A 2013 investigation by the Tampa Bay Times ranked nearly 6000 American charities based on money paid to solicitors over the past decade. The top 50 totalled $\$ 970.6$ million while allocating less than $4 \%$ of collected donations in direct cash aid to their intended causes. ${ }^{5}$

\footnotetext{
${ }^{2}$ The Pennies reports are available at $<$ www.charitiesnys.com $>$. From 2002 to 2012, around 580 telemarketing campaigns were run on behalf of 438 charities annually.

${ }^{3}$ Similar statistics have been documented by other states including California, Colorado, Connecticut, Massachusetts, North Carolina, Ohio, Pennsylvania, Tennessee, and Vermont. For instance, the California Attorney General reported that of the $\$ 294.3$ million that the public donated through telemarketers in 2012, only 36\% was distributed to charities. The same year, $\$ 494$ million was raised in nationwide campaigns including North Carolina residents but only $46 \%$ reached the nonprofits; see $<$ http:/ /oag.ca.gov/charities/publications\#cfrReports $>$ and <https://www.secretary.state.nc.us/csl/ > .

These statistics are also comparable to those for European charities (Sandberg 2006).

${ }^{4}$ See <www.bloomberg.com/news/2012-09-12/charities-deceive-donors-unaware-money-goes-to-atelemarketer.html $>$.

${ }^{5}$ See $<$ www.tampabay.com/americas-worst-charities $>$.
} 
The high cost of paid fundraisers raises legitimate concerns about the accountability of charitable organizations. As such, it has the potential to severely undermine public confidence in the nonprofit sector, which constitutes about $2 \%$ of GDP in the U.S (GivingUSA, 2013). Nevertheless, before introducing any policy, it is important to understand the market for professional fundraising: why it exists despite being so expensive; what it implies about donor motives; whether it is consistent with informed donors (as intended by state regulators); and how it should be intervened by authorities, if necessary. Complicating policy interventions is the fact that a direct regulation of fundraising contracts is prohibited by freedom of speech (Hopkins, 2009). ${ }^{6}$ Regulators in 41 U.S. states including California and New York do, however, have disclosure laws that compel paid solicitors to identify themselves to donors (Fishman and Barrett, 2013). ${ }^{7}$

This paper proposes a first model of outsourced fundraising, featuring one charity, one professional fundraiser and many potential donors. Each donor considers giving only if solicited. ${ }^{8}$ The charity may conduct these (costly) solicitations on its own or outsource them to the professional by promising him a percentage of the donations collected. ${ }^{9} \mathrm{We}$ find that the charity would be unlikely to outsource if, as required by law, the professional revealed himself to donors. Intuitively, under outsourcing, the charity retains the paid solicitor as an agent whose unobserved effort is the number of solicitations (Holmstrom, 1979). To overcome the resulting incentive cost, the charity outsources its fundraising only if the paid solicitor is sufficiently more "efficient" than itself. Indeed, charities often justify the use of paid solicitors by being unequipped to undertake complex, large-scale campaigns as well as their need to focus on core missions. Consistent with agency theory, the

\footnotetext{
${ }^{6}$ The U.S. Supreme Court consistently overturned state laws that limited fundraiser fees. In 1980, the Schaumburg case (444 U.S. 620) overturned a city ordinance prohibiting door-to-door or on-street solicitation of contributions by charitable organizations that do not use at least $75 \%$ of their receipts for charitable purposes. In 1984, the Munson case (467 U.S. 947) invalidated a Maryland statue that similarly prohibited paying fundraisers more than $25 \%$ of the amount raised. In 1988, the Riley case (487 U.S. 781) invalidated a North Carolina law that denied licenses to professional fundraisers whose commissions exceeded $20 \%$. The Riley case also dismissed the law's requirement that a professional fundraiser must disclose to potential donors the average percentage of gross receipts actually turned over to charities in the preceeding year.

${ }^{7}$ As per the Supreme Court ruling on the Riley case, these laws cannot mandate the disclosure of fundraising contracts to donors.

${ }^{8}$ Directly asking donors is considered one of the most powerful fundraising techniques; see Yoruk (2009), Andreoni and Rao (2011), Meer and Rosen (2011), and Edwards and List (2014) for evidence.

${ }^{9}$ Prior to solicitation campaigns, professional fundraisers must often file with the state their contracts with charities. Greenlee and Gordon (1998) found 63.3\% of such contracts between 1991 and 1996 in Pennsylvania were percentage-based. Based on the Pennies report, Keating et al. (2003) similarly concluded "telemarketing arrangements are (explicitly or implicitly) structured with a heavy reliance on a (high) fixed commission rate." Our own inspection of New York and North Carolina data confirm these findings.
} 
charity optimally offers a higher percentage of total receipts to a more efficient solicitor, implying a higher price of giving. Thus, outsourcing is profitable for the charity only if giving is very price-inelastic. That, however, is strongly refuted by empirical evidence on elasticity (Clotfelter, 1985; Randolph, 1995; Auten et al. 2002; Eckel and Grossman, 2003; Bakija and Heim, 2011; and Huck and Rasul, 2011), as well as lab data on preferences for giving (Andreoni and Miller, 2002; Fisman et al. 2007).

In light of this observation, we advance three explanations for the prevalent use of professional fundraisers. First, despite disclosure laws, donors may still be unaware of paid solicitors and continue to give generously. This is consistent with the anecdotal evidence presented in media reports as well as survey evidence indicating largely uninformed giving (Hope Consulting report, 2011) and the strong public confidence in the charitable sector (O'Neill, 2009; Edelman TrustBarometer, 2014). Second, donors may have intense "warm-glow" preference for giving (Andreoni, 1989) and thus be less sensitive to the increased price of giving. And third, in order to improve their watchdog ratings, charities may retain paid fundraisers and shift their campaign fixed costs onto them.

A dynamic extension of our model can further explain why charities are willing to lose on some fundraising campaigns. ${ }^{10}$ We show that as in practice, charities may view paid solicitations as an investment into acquiring new donors who can then be re-solicited. In another extension, we demonstrate that charities with additional funds from government grants and/or repeat donors are less likely to use paid solicitors - though not because additional funds are less valuable to charity but because motivating a paid solicitor is costlier in this case. Together, these extensions suggest that charities are less likely to hire paid solicitors for their established programs but the same charities can afford to become aggressive in establishing new ones.

Apart from the papers mentioned above, our paper relates to a growing theoretical literature on strategic fund-raising by means of: providing prestige and status to donors (Glazer and Konrad, 1996; Harbaugh 1998; Romano and Yildirim, 2001; Barbieri and Malueg, 2014); coordinating donations (Andreoni, 1998; Marx and Matthews, 2000); facilitating informed giving (Vesterlund, 2003; Andreoni 2006; Krasteva and Yildirim, 2013); and organizing lotteries (Morgan, 2000). These papers, however, do not model fundraising as an endogenous, costly undertaking. Fixing donor behavior, Rose-Ackerman (1982) provides a first model of costly fund-raising as a means of informing donors of the charitable cause as

\footnotetext{
${ }^{10}$ The Pennies report reveals that about $10 \%$ of campaigns results in a loss for charities.
} 
in our setting. She shows that fundraising can be "excessive". Andreoni and Payne (2003), Name-Correa and Yildirim (2013), and Perroni et al. (2014) endogenize both the charity and donors' behaviors, but they essentially assume "in-house" fundraising; so outsourcing, which is at the heart of our investigation, is nonissue. We should note that there is also an extensive empirical literature on charitable giving as ably reviewed by List (2011) and Andreoni and Payne (2013).

The remainder of the paper is organized as follows. In the next section, we set up the base model. In Section 3, we characterize the benchmark of in-house fundraising. In Section 4 , we determine an optimality condition for outsourced fundraising and argue that it would contradict evidence if donors were aware of this practice. In Section 5, we advance three explanations for outsourcing, followed by extensions to dynamic fundraising, additional revenue sources from government grants/ repeat donors, and per-call based contracts in Section 6. Section 7 discusses policy and concludes. The proofs of all the formal results appear in the appendix.

\section{Base model}

The economy consists of one charity, one professional fundraiser and many identical donors. Each donor considers giving and participates in a voluntary contribution game only if solicited - perhaps she is uninformed of the current fund-drive or simply procrastinates. ${ }^{11}$ The charity can fundraise in-house or outsource its fundraising to the professional by offering him a percentage $s$ of the donations collected. ${ }^{12}$ Since it is not required by law, $s$ is not disclosed to donors at the time of solicitation, though donors can hold rational expectations about it. We assume that the fundraising technology is represented by a convex, iso-elastic cost function:

$$
C(n ; \alpha)=\frac{n^{1+1 / \alpha}}{1+1 / \alpha}
$$

\footnotetext{
${ }^{11}$ Our model easily accommodates repeat donors who do not need soliciting or cost little to solicit; see Section 6.2. Also, as previously indicated in Footnote 8, there is ample evidence on the power of asking in fundraising.

${ }^{12}$ For the prevalent use of percentage contracts in paid fundraising, see Footnote 9 . We discuss other contract types in Section 6.4. In practice, the contract negotiation between the charity and the professional can be complicated but assuming a more powerful professional will only strengthen our results. Moreover, the exemption of nonprofits from the Do-Not-Call registry seems to have increased telemarketer competition for nonprofits.
} 
where $\alpha>0$ is the "ability" parameter and $n$ is the number of solicitations. ${ }^{13}$ In particular, treating $n$ as a continuous variable, the marginal cost is $C_{n}(n ; \alpha)=n^{1 / \alpha}$, where subscripts refer to partial derivatives throughout. Note that marginal cost is decreasing in $\alpha$; so we say that the fundraising technology is more efficient, the higher $\alpha$ is. ${ }^{14}$ Donors cannot monitor the choice of $n$ and in case of outsourcing, neither can the charity.

On the donor side, we adopt the standard model of giving (Bergstrom et al. 1986). Each contacted person allocates her income $m$ between a private good consumption $x_{i} \geq 0$ and a gift to the charity $g_{i} \geq 0$ without observing others. Units are normalized so that $x_{i}+g_{i}=$ $m$. Let $G=\sum_{i} g_{i}$ be the total donation. Then, the charity's net revenue is $G-C$ for the in-house and $(1-s) G$ for the outsourced fundraising. The charity can provide the public good only if its net revenue is positive. In particular, the public good is provided at the levels: $\bar{G}=\max \{G-C, 0\}$ and $\bar{G}=(1-s) G$ for the in-house and outsourced fundraising, respectively. Person $i$ 's preferences are represented by an increasing and quasi-concave utility function:

$$
u_{i}=u\left(x_{i}, \bar{G}\right)
$$

Let $f(m, p)$ be individual (Marshallian) demand for the public good whose relative price is $p$. We assume that both public and private goods are normal so that $0<p f_{m}<1$. Below, we will frequently refer to price and income elasticities of demand: $\varepsilon^{p}=\frac{p \times f_{p}}{f}$ and $\varepsilon^{m}=\frac{m \times f_{m}}{f}$.

To establish a benchmark, we begin our investigation by in-house fundraising and then turn to outsourcing.

\section{In-house fundraising}

Suppose that the charity fundraises itself and that this is commonly known by donors. Anticipating a (Nash) equilibrium gift $g^{I}$ from each solicitation, ${ }^{15}$ the charity chooses the number of solicitations to maximize net revenues:

$$
\bar{G}^{I}=\max _{n}\left[n g^{I}-C\left(n ; \alpha_{I}\right)\right]
$$

\footnotetext{
${ }^{13}$ For simplicity, each solicitation is assumed to reach the donor. Moreover, with little loss of generality, fixed costs of fundraising are ignored in the main analysis but briefly discussed in Section 5.3.

${ }^{14}$ The total cost $C($.$) is also decreasing in \alpha$ if and only if $n>e^{\frac{\alpha}{1+\alpha}}$ (or if $n \geq 3$ ) which we assume to hold for consistency.

${ }^{15}$ Since donors do not observe the number of solicitations, their gifts are fixed from the charity's perspective. Moreover, in the proof of Proposition 1, we show that equilibrium gifts must be the same.
} 
The first-order condition requires that $g^{I}=C_{n}\left(n ; \alpha_{I}\right)$. That is, the optimal number of solicitations equates the marginal revenue, which is the last donation, to its marginal cost. Employing Eq.(1), this condition reduces to:

$$
n=\left(g^{I}\right)^{\alpha_{I}}
$$

All else equal, the charity reaches out to more people, the larger the expected gift and/or the more efficient its technology is. In equilibrium, both the donors and the charity correctly conjecture strategies; hence $n=n^{I}$ and $g^{I}=g\left(n^{I}\right)$. Our first result characterizes in-house fundraising. ${ }^{16}$

Proposition 1 Under in-house fundraising, there is a unique and symmetric equilibrium. In equilibrium, as the fundraising technology becomes more efficient, namely $\alpha_{I}$ gets larger, the number of solicitations, $n^{I}$; the total cost, $C^{I}$; the gross donations, $G^{I}$; and the net revenues, $\bar{G}^{I}$ all increase whereas the individual gift, $g^{I}$ decreases.

As expected, a more efficient charity contacts more individuals and incurs a higher total cost as a result. Since free-riding intensifies in a larger population, each contacted individual gives less; but this reduction is not enough to diminish gross or net donations. The latter highlights a donor incentive to partially cover the fundraising cost.

The cost-to-donation ratio for the charity can also be readily determined. From Eqs. (1) and (2), note that the equilibrium total donation is: $G^{I}=\left(1+1 / \alpha_{I}\right) C^{I}$, which reveals

$$
r^{I} \equiv \frac{C^{I}}{G^{I}}=\frac{\alpha_{I}}{1+\alpha_{I}}
$$

Evidently, $r^{I}$ is increasing in $\alpha_{I}$. That is, a more efficient charity, while raising more funds, has a higher cost-to-donation ratio! Most starkly, the ratio is close to 1 for the most efficient charity. The intuition is that an optimizing charity solicits until its cost-to-donation ratio for the last donor is 1 . Since a more efficient charity has a flatter marginal cost curve, its (average) ratio ends up higher. This finding has two important implications.

First, though simple and often utilized by leading watchdogs such as Charity Navigator and CharityWatch, the cost-to-donation ratio is an unreliable measure for ranking

\footnotetext{
${ }^{16}$ Given our focus on a fundraising market, we rule out the trivial equilibrium in which it does not exist. Specifically, conjecturing the total solicitation $\operatorname{cost} C>0$, there can be a zero-contribution equilibrium among donors much like in Andreoni's (1998) non-convex public good provision; but it is never reached in our setting since $C$ is endogenous to solicitations. That is, a fundraiser who anticipates a negative net revenue would not start the campaign in the first place and if she starts one, her expectation of positive contributions must be correct in a Nash equilibrium.
} 
charities. As such, our finding theoretically supports the critics of this measure (Steinberg, 1991; Karlan, 2011). Nevertheless, there is some evidence that donors care about cost-todonation ratios and best practice standards promoted by industry experts and watchdogs (Cnaan et al. 2011; Gordon et al. 2009; Brown et al. 2014; Yoruk 2014). Thus, second, our finding might also explain why some charities fall short of maximizing net-revenues and instead behave as "satisficers" who set revenue goals (Khanna et al. 1995; Okten and Weisbrod 2000; and Andreoni and Payne, 2011). The following corollary, which directly obtains from Eq.(3), shows that a goal-setting charity is likely to be more efficient.

Corollary 1 Suppose that donors respond to watchdog ratings and that watchdogs consider the cost-to-donation ratio up to $r^{\text {wd }}$ to be "acceptable". Then, a charity with $\alpha_{I}>\frac{r^{\text {rod }}}{1-r^{\text {rwd }}}$ falls short of maximizing net revenues by soliciting too few donors whereas a charity with $\alpha_{I} \leq \frac{r^{\text {rod }}}{1-r^{\text {rod }}}$ maximizes net revenues.

Corollary 1 predicts that more charities that are relatively efficient will turn satisficers as the "acceptable" rating grows more stringent. For a charity that is inefficient in fundraising, a viable alternative is to outsource it to a more experienced, better-equipped solicitor such as a telemarketing firm. Such efficiency-based outsourcing is, however, difficult to rationalize if donors are made aware of the practice, as we formalize next.

\section{Outsourcing with aware donors: near impossibility}

Suppose that the charity contracts out its fundraising to a professional solicitor whose efficiency parameter is $\alpha_{0}$. Also suppose that the professional complies with the states' disclosure laws, and identifies himself as well as the sponsoring charity to the donors at the point of solicitation. The charity cannot directly monitor the number of solicitations conducted by the professional; to motivate, the charity offers him a percentage $s$ of the funds raised. Donors observe neither the percentage nor the number of solicitations. This means that from the fundraiser's perspective, donations are fixed and determined in equilibrium.

Upon accepting the contract and expecting a (unique) equilibrium gift $g^{o}$ from each solicitation, ${ }^{17}$ the professional solicits $n$ donors to maximize his profit:

$$
n \in \arg \max _{\widehat{n}}\left[s \hat{n} g^{o}-C\left(\widehat{n} ; \alpha_{o}\right)\right] .
$$

\footnotetext{
${ }^{17}$ As with the in-house benchmark, it is readily verified that equilibrium gifts are equal.
} 
The professional accepts the contract if it yields a nonnegative profit:

$$
\Pi=\operatorname{sng} g^{o}-C\left(n ; \alpha_{o}\right) \geq 0 .
$$

Taking these incentive and individual rationality constraints into account, the charity sets the percentage $s$ to maximize its net proceeds:

$$
\begin{gathered}
\overline{\mathrm{G}}^{o}=\max _{s, n}(1-s) n g^{o} \\
\text { s.to (IC) and (IR). }
\end{gathered}
$$

Note that the (IR) constraint is trivially satisfied because the professional can ensure a zero profit by soliciting no one. Thus, in equilibrium the professional must receive a positive profit, namely $\Pi^{o}>0$. This is an "incentive cost" to the charity. The first-order condition from (IC) requires that $s g^{o}=C_{n}\left(n ; \alpha_{o}\right)$. As with in-house fundraising, the professional solicits until his marginal revenue, which is the agreed percentage of the last donation, equals his marginal cost. Using Eq.(1), the professional's strategy simplifies to:

$$
n=\left(s g^{o}\right)^{\alpha_{o}}
$$

Not surprisingly, the solicitation effort intensifies with a higher percentage retained and a larger expected gift. Inserting Eq.(4) into (OF), the charity's objective becomes

$$
\bar{G}^{o}=\max _{s}(1-s)\left(s g^{o}\right)^{\alpha_{o}} g^{o}
$$

whose unique solution is:

$$
s^{o}=\frac{\alpha_{o}}{1+\alpha_{o}} .
$$

Three properties of the optimal (percentage) contract, $s^{o}$ are worth noting. First, $s^{o}$ is increasing in $\alpha_{0}$ : a more efficient solicitor is offered a larger share of the donations. The trade-off is easily seen from (5): a larger share reduces the charity's return but motivates the solicitor; and motivating a more efficient solicitor is less costly. ${ }^{18}$ Second, the share offered to the professional can be quite high. For instance, the solicitor with a quadratic cost, $\alpha_{o}=1$, is paid half of the total donation. This observation may rationalize the empirical evidence that telemarketing companies specializing in fundraising often retain more than half of the donations and the charities agree to it. This does not, however, mean that the

\footnotetext{
${ }^{18}$ This comparative static is consistent with that for a standard principal-agent relationship: the agent is promised a larger fraction of the profit as his effort cost becomes less convex (Holmstrom, 1979).
} 
charity receives little. From Eqs.(1) and (4), it is readily found that $\bar{G}^{o}=\left(1+1 / \alpha_{o}\right) \times \Pi^{o}$; that is, the charity's net revenues actually exceed the fundraiser's profit by a fraction of $1 / \alpha_{0}$. Third, because donors cannot observe or verify the fundraising contract at the time of solicitation and adjust their gifts, the contract depends only on the solicitor's technology - not on donors' preferences. This dichotomy will prove useful when we discuss voluntary contract disclosure in Proposition 3.

For the charity to outsource, the professional must be significantly more efficient than the charity itself to overcome the incentive cost mentioned above. In particular, the charity's net revenue must grow with the fundraiser's efficiency; that is, for outsourcing to be profitable for the charity, it is necessary that $\frac{d}{d \alpha_{0}} \bar{G}^{0}>0$. There is, however, a price effect countering such revenue growth. Note that the (relative) price of giving under outsourcing is:

$$
p^{o} \equiv \frac{1}{1-s^{0}}=1+\alpha_{o}
$$

which exceeds the price of 1 under in-house fundraising, and rises with the professional's efficiency owing to a larger percentage paid to him. Intuitively, if giving is very priceinelastic, then donations should be affected little from outsourcing and as a result, the charity may benefit from hiring a professional. By the same token, if giving is very priceelastic, then the charity is unlikely to gain from outsourcing. The following result confirms this intuition. In its statement, recall that $\varepsilon^{p}$ denotes the price elasticity of demand for the public good.

Proposition 2 Under outsourcing, there is a unique and symmetric equilibrium. In equilibrium, the charity's net revenue is increasing in fundraiser efficiency, i.e., $\frac{d}{d \alpha_{0}} \bar{G}^{o}>0$, if and only if $\left|\varepsilon^{p}\right|<$ $p f_{m} \times\left(1+\frac{\ln n}{\alpha_{0} n}\right)$, where $p=p^{o}$ and $n=n^{o}$.

To understand Proposition 2, note that the ratio $\frac{\ln n}{n}$ is likely to be negligible for mass solicitations. ${ }^{19}$ Given this, the condition in Proposition 2 reduces to: $\left|\mathcal{E}^{p}\right| \leq p f_{m}$. Since $p f_{m}<1$ by normality, this means that outsourcing based on fundraiser efficiency can be justified only if giving is sufficiently price-inelastic, as the intuition suggested. In our two-good economy, this is equivalent to the private good being a gross complement to the

\footnotetext{
${ }^{19}$ In particular, $\frac{\ln n}{n}$ converges to 0 at the rate of $\frac{1}{n}$. For instance, $\frac{\ln n}{n}=.046, .012, .006$ for $n=100,500,1000$. Moreover, recall from Eq.(6), a solicitor who receives at least half of donations must have efficiency $\alpha_{o} \geq 1$.
} 
public good. ${ }^{20}$ Thus, for an efficiency-based outsourcing, some complementarity between the goods is also necessary.

The evidence, however, does not support outsourcing. For one, there is a wide empirical consensus that charitable giving is price-elastic, namely $\left|\varepsilon^{p}\right|>1 .{ }^{21}$ Second, notice the term $p f_{m}$ can be written: $\frac{p f}{m} \times \varepsilon^{m}$, where $\frac{p f}{m}$ is the fraction of income spent on charity and $\varepsilon^{m}$ is the income elasticity of donation. The fraction of personal income allocated to charity hovers around $2 \%$ in the U.S. (Giving USA, 2013). Furthermore, most studies estimate the income elasticity to be less than 1 - around .7 (Auten et al., 2002; Bakija and Heim, 2011). Hence, a reasonable estimate for $p f_{m}$ is roughly .014, which is far below the price elasticity, $\left|\varepsilon^{p}\right| .^{22}$

Additional and equally strong evidence against outsourcing comes from lab data on individual preferences for giving. Both Andreoni and Miller (2002), and Fisman et al. (2007) experimentally find that most subjects exhibit a much higher degree of substitution between giving self and giving to others than Leontief. To see what this implies in our context, consider first Leontief preferences: $u_{i}=\min \left\{x_{i}, \bar{G}\right\}$, for which demand for the public good is: $f(m, p)=\frac{m}{1+p}$, implying that $\left|\varepsilon^{p}\right|=p f_{m}=\frac{p}{1+p}$. Thus, with Leontief, efficiencybased outsourcing can indeed be rationalized - but barely. That is, our outsourcing criterion in Proposition 2 is unlikely to hold for less than perfect complements observed in lab data, as we demonstrate next.

Example 1 (CES utility) Suppose

$$
u_{i}=\left(a x_{i}^{\rho}+(1-a) \bar{G}^{\rho}\right)^{\frac{1}{\rho}},
$$

where $\rho \in(-\infty, 1)$. Letting $r=\frac{\rho}{\rho-1}$ and $A=(a /(1-a))^{1-r}$, demand for the public good is: $f(m ; p)=\frac{1}{A p^{1-r}+p} m ;$ hence

$$
p f_{m}=\frac{p^{r}}{A+p^{r}} \text { and }\left|\varepsilon^{p}\right|=1-r \frac{A}{A+p^{r}} .
$$

\footnotetext{
${ }^{20}$ This conclusion directly follows from the donor's budget constraint: $x(m, p)+p f(m, p)=m$. Differentiating with respect to $p$, we obtain

$$
\frac{\partial}{\partial p} x(.)={ }^{\operatorname{sign}}\left|\varepsilon^{p}\right|-1
$$

${ }^{21}$ See, for instance, Clotfelter (1985), Randolph (1995), Auten et al. (2002), Eckel and Grossman (2003), Bakija and Heim (2011), and Huck and Rasul (2011). Andreoni and Payne (2013) briefly summarizes the literature.

${ }^{22}$ To be sure, recent empirical studies have distinguished between transitory and persistent elasticities of giving depending on the periods of tax laws. It seems natural to assume that the effects of outsourcing are temporary. In this respect, Randolph (1995) estimates $\left|\varepsilon^{p}\right|=1.55$ and $\varepsilon^{m}=.58$ whereas Auten et al (2002) estimate $\left|\varepsilon^{p}\right|=.4$ and $\varepsilon^{m}=.29$. Despite the mixed evidence, our outsourcing condition is violated.
} 
Since $\frac{\ln n}{n} \leq \frac{1}{e}$, Proposition 2 reveals that

$$
\frac{d}{d \alpha_{o}} \bar{G}^{o}<0 \text { if }\left|\varepsilon^{p}\right| \geq p f_{m} \times\left(1+\frac{1}{e \times \alpha_{o}}\right) .
$$

Setting $p=1+\alpha_{o}$, it follows that $\frac{d}{d \alpha_{o}} \bar{G}^{o}<0$ if eA $(1-r) \alpha_{o}-\left(1+\alpha_{o}\right)^{r} \geq 0$, or equivalently if

$$
e(a /(1-a))^{1 /(1-\rho)} \alpha_{o}-(1-\rho)\left(1+\alpha_{o}\right)^{-\rho /(1-\rho)} \geq 0 .
$$

The left-hand side of this inequality is increasing in $\alpha_{o}$; and it becomes negative for $\alpha_{0} \rightarrow 0$ and positive for $\alpha_{0} \rightarrow \infty$. Thus, there is a unique threshold $\underline{\alpha}(\rho, a)>0$ such that $\frac{d}{d \alpha_{0}} \bar{G}^{o}<0$ if $\alpha_{o} \geq \underline{\alpha}(\rho, a)$. Moreover, $\underline{\alpha}(\rho, a)$ is decreasing in both $\rho$ and $a$, with $\underline{\alpha}(\rho, .5)=.03, .32, .37, .42$, and .96 for $\rho=.9, .1,0,-.1$, and -.9 , respectively.

Example 1 says that an outsourcing charity actually becomes worse off by hiring a more efficient fundraiser if individual preferences display enough selfishness (i.e., a high a) and/or enough substitution between private good and charity. This makes sense because, as alluded to above, a more efficient fundraiser is promised a greater percentage of donations, raising the price of giving. With enough selfishness and/or substitution, this causes donors to significantly cutback on their gifts, diminishing net revenue for the charity. Estimating CES preferences, Andreoni and Miller report that only 25 out of 173 subjects exhibit Leontief preferences, namely $\rho=-\infty$, while the rest (86\%) have $a \geq .5$ and $\rho \geq-$.36. Using a similar method, Fisman et al. (2007) uncover that only 2 out of 65 subjects can be rationalized by Leontief preferences while the remaining (97\%) have $a \geq .5$ and $\rho \geq-.9$. Example 1 thus implies that for most individuals in these two experiments, $\underline{\alpha}(\rho, a) \leq .96$. Since a professional solicitor who keeps at least half of donations (as suggested by the telemarketing evidence) corresponds to $\alpha_{0} \geq 1$ by Eq.(6), Example 1 also implies that the charity's net revenue is decreasing in fundraiser efficiency, making outsourcing unprofitable.

In sum, based on rich data on charitable giving, we cannot rationalize outsourced fundraising if donors are aware of this practice - not necessarily of the actual percentage. The apparent reluctance of professional solicitors to inform donors of their fundraising contracts at the point of solicitation reinforces this conclusion. ${ }^{23}$ To see why, suppose that

\footnotetext{
${ }^{23}$ In the 1988 Riley case alluded to in the introduction, a coalition of professional fundraisers and charitable organizations opposed to a North Carolina law that mandated the disclosure of fundraising commissions to donors. The Supreme Court held that such disclosure might unduly impair nonprofits' ability to raise funds. For an interesting discussion of nonprofit disclosure laws in the U.S. and Europe, see Sandberg (2006).
} 
giving is price-elastic as suggested by the data. If the fundraising contract were to be disclosed to donors, then the charity would optimally lower the fundraiser's percentage to both control the price effect and (implicitly) commit to the number of solicitations. While, compared to nondisclosure, a lower percentage would benefit the charity, it would hurt the fundraiser. We formalize this intuition in,

Proposition 3 Suppose that the charity outsources and the fundraiser verifiably discloses its contract to donors at the point of solicitation. If giving is price-elastic, $\left|\varepsilon^{p}\right| \geq 1$, then the fundraiser receives a lower percentage and is worse off than under nondisclosure. The charity is, on the other hand, better off under contract disclosure. Formally, $s^{o, d}<s^{o} ; \Pi^{o, d}<\Pi^{o} ;$ and $\bar{G}^{o, d}>\bar{G}^{o}$.

Proposition 3 confirms our modeling assumption that the fundraiser does not voluntarily disclose his contract to donors. It also explains states' efforts to inform donors of percentages retained by professional fundraisers. Note that Proposition 3 holds even when $\left|\varepsilon^{p}\right|=1$; hence, by continuity, it also holds for $\left|\varepsilon^{p}\right|$ less than but close to 1 - consistent with experimental data that shows some complementarity between public and private goods. The reason is that even if the price effect is not too severe, the charity would still want to lower the fundraiser's percentage to discourage excessive solicitations. The obvious question, however, remains:

\section{Why do charities outsource fundraising?}

We offer three possible answers in this section. First, donors are simply unaware of professional solicitations. Second, donors are also "warm-glow" or joy givers and therefore less sensitive, though not insensitive, to the price of giving. And third, for fundraising cam-

paigns that involve significant fixed costs, charities have an incentive to shift these costs onto fundraisers in order to improve their watchdog ratings.

\subsection{Unaware donors}

Common to the media accounts alluded to in the Introduction is the fact that the interviewed donors often did not know about paid solicitations or high percentages retained by the solicitors. For instance, in the Bloomberg story, upon learning that all of the proceeds from a $\$ 5.3$ million campaign conducted on behalf of the American Cancer Society 
went to the telemarketing company, a 30-year fundraiser of New York University reportedly said:

"I didn't know about it. It's deceitful...And I am in the field. So how can you expect donors to know that?"

When asked about such losing campaigns, a senior manager at the Cancer Society responded:

"If we came into it and said, 'Geez, I'm not going to make a dime on this,' do you think we would have anyone who would give us money?"

These accounts are consistent with states' efforts to inform donors about telemarketing activities as well as survey evidence pointing to uninformed giving (Hope Consulting, 2011) and strong public confidence in the charitable sector ( $\mathrm{O}^{\prime}$ Neill, 2009; Edelman TrustBarometer, 2014). ${ }^{24}$ Proposition 4 shows that unlike with aware donors, the charity might optimally hire a paid solicitor if donors are unaware.

Proposition 4 Suppose that donors are unaware of paid solicitations and continue to make their in-house gifts, namely $g^{I}=g^{o}=g$. Then, a charity with technology $\alpha_{I}$ hires a paid solicitor with technology $\alpha_{o}$ if and only if $\alpha_{o}>\underline{\alpha}\left(g, \alpha_{I}\right)$ where $\underline{\alpha}()>.\alpha_{I}$ is a unique cutoff. Moreover, $\underline{\alpha}($.$) is$ decreasing in $g$ and increasing in $\alpha_{1}$; that is, the charity is more likely to outsource its fundraising (1) the higher its expected in-house gift is or (2) the less efficient its own solicitation technology is.

The intuition behind outsourcing is that unaware donors do not respond to the increase in the price of giving due to outsourcing. This is a reminiscent of the tax salience literature where consumers are found to react less to nonsalient price changes (Chetty et al., 2009; Finkelstein, 2009). Interestingly, the charity is more likely to outsource its fundraising when donors are more generous toward its cause. While a more generous gift raises the charity's net revenues regardless of the mode of fundraising, it further raises net revenues from outsourcing by motivating the solicitor (see Eq.(4)) and in turn lowering the incentive cost for the charity. The same logic explains why a more efficient charity is less likely to outsource: by soliciting a larger set of donors, a more efficient charity receives a less

\footnotetext{
${ }^{24}$ In these studies, survey evidence shows that people trust nonprofits more than they trust the government or businesses to address pressing social problems.
} 
generous (in-house) gift from each donor, which de-motivates the solicitor and raises the incentive cost for the charity.

Proposition 4 implies that with unaware donors, charitable motives that increase gifts should also increase the likelihood of outsourcing. Most significantly, Proposition 4 predicts that charitable causes that carry intense warm-glow preference should be the prime candidates for paid solicitations. This prediction appears compatible with a leading telemarketing firm's strategy:

“Telephone purchases and donations are made on impulse. These are dictated not by reason or logic but by feelings of emotion. We are very familiar with the emotions of fundraising: sympathy, fear, anger, guilt, etc." (Bloomberg Markets, 2012) $)^{25}$

To fully understand this business strategy, and thus the charity's incentive to outsource, we also need to understand whether outsourcing would continue to be profitable for the charity if, as required by law, warm-glow donors were made aware of paid solicitations. As we show next, this is the case if donors are primarily warm-glow givers.

\subsection{Aware warm-glow donors}

As in Section 4, suppose that the charity outsources its fundraising to a professional with efficiency $\alpha_{o}$ and that the professional discloses this fact to donors at the point of solicitation. Donors, however, now possess an added motive of warm-glow à la Andreoni (1989). Specifically, when the fundraiser retains a percentage $s$ of the funds collected, donor $i$ 's utility is given by:

$$
u_{i}=u\left(x_{i}, \bar{G}, \bar{g}_{i}\right),
$$

where $\bar{G}=(1-s) G$ and $\bar{g}_{i}=(1-s) g_{i}$. As before the donor receives utility from private consumption $x_{i}$ and public good production $\bar{G}$, but he now also receives a warm-glow utility from the fraction of his donation that goes toward the public good, $\bar{g}_{i}{ }^{26}$

Conjecturing $s$ and others' total contribution $G_{-i}$, donor $i$ maximizes his utility in (7) subject to budget constraint: $x_{i}+g_{i}=m$. Denoting by $p=\frac{1}{1-s}$ the price of giving and

\footnotetext{
${ }^{25}$ Small et al. (2007) experimentally supports this fundraising strategy: people give more to the causes they identify with, than to the ones they reason about.

${ }^{26}$ Hence, we implicitly assume that donors do not obtain warm-glow from simply paying for the fundraising cost. Results would only be stronger if they did.
} 
$\bar{G}_{-i}=(1-s) G_{-i}$ others' net contribution, $i$ 's program can be re-stated:

$$
\begin{gathered}
\max _{x_{i}, \bar{G}} u\left(x_{i}, \bar{G}, \bar{G}-\bar{G}_{-i}\right) \\
\text { s.to } x_{i}+p \bar{G}=M \\
\bar{G} \geq \bar{G}_{-i},
\end{gathered}
$$

where $M \equiv m+p \bar{G}_{-i}$ is the "social income". This formulation reduces to Andreoni's for $s=0$. Ignoring the second constraint (which holds in equilibrium), let $\bar{G}=\bar{f}(m+$ $\left.p \bar{G}_{-i}, \bar{G}_{-i} ; p\right)$ be the solution to (WG) where $\bar{f}$ is donor $i$ 's Nash supply. Also let $\bar{f}_{m^{\prime}} \bar{f}_{w^{\prime}}$ and $\bar{f}_{p}$ be the respective partial derivatives, signifying propensity to give due to altruism, warm-glow, and price increase. Normality of the goods implies that $0<p \bar{f}_{m}<1 ; \bar{f}_{w} \geq 0$; and $\bar{f}_{p}<0$. Note that $\bar{f}_{w}=0$ refers to a purely altruistic donor, who cares only about the charitable output, as in the base model, whereas $p \bar{f}_{m}+\bar{f}_{w}=1$ refers to a pure warm-glow giver who is unresponsive to others' contributions. To capture both motives for giving here, we assume $0<p \bar{f}_{m}+\bar{f}_{w} \leq 1$.

From the fundraiser's perspective, gifts are fixed in equilibrium; so the optimal contract and the price of giving stay the same as in pure altruism in Section 4 . The following result extends Proposition 2 and derives the condition under which the charity's net revenue is increasing in fundraiser's efficiency - a necessary condition for outsourcing. In its statement, $\bar{\varepsilon}^{p}=\frac{p \bar{f}_{p}}{\bar{f}}$ represents the price elasticity of Nash supply.

Proposition 5 Consider warm-glow giving described in this subsection and suppose that donors are aware of paid solicitations. Then, there is a unique and symmetric equilibrium. In equilibrium, the charity's net revenue is increasing in fundraiser efficiency, i.e., $\frac{d}{d \alpha_{0}} \bar{G}^{0}>0$, if and only if $\left|\bar{\varepsilon}^{p}\right|<$ $p \bar{f}_{m} \times\left(1+\frac{\ln n}{\alpha_{0} n}\right)+\bar{f}_{w} \times\left(\frac{1}{n}+\frac{\ln n}{\alpha_{0} n}\right)$, where $p=1+\alpha_{o}$ and $n=n^{o}$.

Clearly, by setting $\bar{f}=f$ and $\bar{f}_{w}=0$, the outsourcing condition coincides with that found in Proposition 2. To discern the role of warm-glow, note that for mass solicitations, i.e., large $n$, the condition in Proposition 5 approximately becomes: $\left|\bar{\varepsilon}^{p}\right| \leq p \bar{f}_{m}$. Since $p \bar{f}_{m}<1$ by normality, as with no warm-glow, the Nash supply must be sufficiently priceinelastic, implying that private good must be a gross complement to the public good. It is intuitive that with an added warm-glow motive, giving should be less price sensitive; that is, it should be that $\left|\bar{\varepsilon}^{p}\right| \leq\left|\varepsilon^{p}\right|$. Moreover, all else equal, we expect a warm-glow donor to give a larger fraction of her marginal dollar than a pure altruist; that is, we expect 
that $p f_{m} \leq p \bar{f}_{m}$. Taken together, the warm-glow motive is likely to relax the outsourcing condition. To determine if it is satisfied, however, we examine a CES example - extending Example 1.

Example 2 (CES with warm-glow) Suppose

$$
u_{i}=\left[a x_{i}^{\rho}+(1-a)\left((1-\omega) \bar{G}+\omega \bar{g}_{i}\right)^{\rho}\right]^{\frac{1}{\rho}},
$$

where $\rho \in(-\infty, 1)$ and $\omega \in[0,1]$. Again, letting $r=\frac{\rho}{\rho-1}$ and $A=(a /(1-a))^{1-r}$, we find $\bar{f}\left(M ; \bar{G}_{-i} ; p\right)=\frac{1}{A p^{1-r}+p} M+\frac{\omega A}{A+p^{r}} \bar{G}_{-i}$, which yields

$$
p \bar{f}_{m}=\frac{p^{r}}{A+p^{r}} \text { and } \bar{f}_{w}=\frac{\omega A}{A+p^{r}},
$$

and

$$
\left|\bar{\varepsilon}^{p}\right|=\left|\varepsilon^{p}\right|-\frac{\omega(1-r) A}{A+p^{r}}\left(\frac{n-1}{n}\right),
$$

where $\left|\mathcal{E}^{p}\right|=1-r \frac{A}{A+p^{r}}$ is the price elasticity found in Example 1. Proposition 5 implies that

$$
\frac{d}{d \alpha_{o}} \bar{G}^{o}>0 \Longleftrightarrow(1-r)(1-\omega) A \leq\left(p^{r}+\omega A\right) \frac{\ln n}{\alpha_{o} n}+\frac{r \omega A}{n} .
$$

For $n \rightarrow \infty, \bar{G}^{o}$ is increasing in $\alpha_{o}$ if and only if $\omega \rightarrow 1$ or $\rho \rightarrow-\infty$. For $\omega=1, \bar{G}^{o}$ is increasing in $\alpha_{o}$ if $\rho \leq 0$; and it is decreasing if $\rho \rightarrow 1$.

Evidently, a higher $\omega$ implies a stronger warm-glow preference, with $\omega=1$ representing a pure warm-glow giver. Example 2 reveals that in addition to unaware donors, the charity may outsource its mass solicitations to a professional if warm-glow is the sole charitable motive. It also reveals that mass solicitations are optimal for aware pure warm-glow givers if warm-glow and private good are complements, or else substitution between them is not too high so that the negative price effect is not pronounced. This is consistent with the literature on charitable motives: in general, donors are found to have both altruistic and warm-glow preferences for giving but the latter is likely to dominate in a large economy (Ribar and Wilhelm, 2002; Yildirim, 2013). More interestingly, the observation from Example 2 is also consistent with the telemarketing strategy alluded to above, in which the fundraiser promises to make donors act solely on their emotions such as "sympathy, fear, anger, guilt, etc.". While we are unaware of any direct evidence on which charitable causes arouse such emotions, Keating et al. (2003) observe that about one-third of telemarketing campaigns in New York's Pennies reports from 1994 to 2001 were police-related and 
another one-third were conducted on behalf of activist or advocacy organizations, civic clubs, groups that support the military, and illness-related associations. In a comparable study that exploited Pennsylvania data from 1991 to 1996, Greenlee and Gordon (1998) find that charities in the advocacy, disease/disorder, youth development and public safety subsectors were more likely to hire paid solicitors. Andreoni and Payne (2011) support these findings. Across a wide range of social welfare and community-based charities, they measure about $75 \%$ crowding out but attribute almost all of it to reduced fundraising and little to donor response, implying strong warm-glow for these charities. For international relief and development organizations, Ribar and Wilhelm (2002) also present compelling evidence of warm-glow giving; so these organizations may be prone to using professional fundraisers - at least for their new projects.

\subsection{Improving watchdog ratings}

Our analysis suggests that a charity which is net-revenue maximizing but unequipped to run complex, large-scale campaigns hires a professional solicitor only if the professional is significantly more efficient. While net-revenue maximization is a reasonable objective, ${ }^{27}$ some charities might be more concerned about their cost-to-donation ratios in order to receive better watchdog ratings and more donations as a result (Gordon et al. 2009; Cnaan et al. 2011; Brown et al. 2014; Yoruk 2014). When a fundraising campaign involves a significant fixed cost due, for instance, to its planning and staff training, outsourcing may indeed help lower the ratio. To see this formally, let $K>0$ be the fixed cost of fundraising, which we have ignored so far. Then, the in-house ratio in Eq.(3) is modified to be:

$$
r^{I, K} \equiv \frac{C^{I}+K}{G^{I}}=\frac{\alpha_{I}}{1+\alpha_{I}}+\frac{K}{G^{I}}
$$

Under outsourcing, recall that absent the fixed cost, the professional earns a positive profit, namely $\Pi^{o}>0$. Thus, the professional is willing to absorb the additional cost as long as $K \leq \Pi^{o}$, leaving the charity's cost-to-donation ratio under outsourcing intact: ${ }^{28}$

$$
r^{o, K} \equiv s^{o}=\frac{\alpha_{o}}{1+\alpha_{o}}
$$

\footnotetext{
${ }^{27}$ As previously discussed in Section 3, the evidence on charities' objectives is mixed. The net-revenue maximization is, however, often adopted in theoretical studies.

${ }^{28}$ The same conclusion also holds for $K>\Pi^{\circ}$, though less trivially since the fundraiser's (IR) - not (IC) constraint would bind in this case.
} 
Comparing Eqs.(8) and (9), it is evident that $r^{o, K}<r^{I, K}$ for $\alpha_{I}=\alpha_{o}=\alpha$. In words, the charity will attain a lower cost-to-donation ratio under outsourcing even if the fundraiser is no more efficient solicitor than itself. The reason is evident: by shifting the fixed cost onto the fundraiser, the charity improves its cost-to-donation ratio.

\section{Extensions}

To further understand the market for professional fundraising, we extend our model to dynamic fundraising in which paid solicitations are considered as an investment into donor acquisition. We then examine how additional funding sources as well as heterogenous donors affect the outsourcing decision. Finally, we compare percentage and per-call based contracts - two of the most used in practice.

\subsection{Professional fundraising as an investment}

It is not uncommon that charities may actually incur a loss on some telemarketing campaigns. For instance, the "Pennies for Charity" report reveals that 91 out of 589 telemarketing campaigns in 2012 yielded a loss to the charity. One explanation for this phenomenon is that the professional fundraiser solicits a "cold" list of donors, with an understanding that the list is then turned over to the charity for future solicitations. In particular, professional fundraising is viewed as an investment into acquiring new donors. To formalize, consider a multi-period extension of our base model with unaware donors so outsourcing is possible. In period 1, the fundraiser (successfully) solicits $n$ new donors in return for a share $s$ of donations. In the remaining $T-1$ periods, the charity re-solicits the same donors at no additional cost. The charity discounts future revenues by $\delta$ but, for simplicity, we assume that donors are short-sighted. ${ }^{29}$

Let $g$ be the (equilibrium) gift from each solicitation. Then, the charity's discounted net revenue is

$$
\bar{G}^{t}=\left(1-s+\delta+\ldots+\delta^{T-1}\right) n g .
$$

Since the fundraiser is hired only in period 1, the number of solicitations again is dictated by Eq.(4); that is, $n=(s g)^{\alpha_{o}}$. Inserting this into Eq.(10) and maximizing it with respect to

\footnotetext{
${ }^{29} \delta$ can also be interpreted as the probability of losing donors each period.
} 
$s$, we find the optimal contract:

$$
s^{o, T}=\left(\frac{1-\delta^{T}}{1-\delta}\right) \frac{\alpha_{o}}{1+\alpha_{o}} .
$$

Clearly, $s^{o, T}$ is increasing in $T$ and $\delta$. That is, as the charity cares more about future returns, it motivates the fundraiser to solicit a longer list of new donors by offering him a larger percentage. In fact, it is now possible that the percentage exceeds 1 , implying a loss

for the charity for the initial $t=\ln \left(\frac{1+\alpha_{0} \delta^{T}}{1+\alpha_{0}}\right) / \ln \delta$ periods, where $t$ is increasing in $\delta, T$, and $\alpha_{0}$ as expected.

It is worth noting that investing into new donors can be a viable strategy only for large charities that have additional resources to pay for it. Our analysis predicts that it is such large charities that are also likely to promise a significantly high percentage to professional fundraisers on new campaigns. This seems consistent with the 2012 Bloomberg report in which the featured telemarketing company had several of the America's biggest charities as its clients. This is also confirmed by Greenlee and Gordon (1998) who empirically found professional solicitor charities to be significantly larger than nonsolicitor charities.

\subsection{Government grants and repeat donors}

Up to now, we have assumed that the single source of revenue for the charity is new donors - perhaps the charitable program itself is new. However, for an established program, the charity may also have repeat donors who cost little to solicit. Moreover, many charities receive government grants. As the following result shows, outsourced fundraising becomes less pronounced in both cases.

Proposition 6 Let $R \geq 0$ and $n_{0} \geq 0$ be the government grant and the number of repeat donors, respectively. Suppose $f(m+R)>R$ and that donors are unaware of professional solicitations. Then, a charity with technology $\alpha_{I}$ uses a professional solicitor with technology $\alpha_{o}$ if and only if $\alpha_{o}>\widehat{\alpha}\left(R, n_{0}\right)$ where $\widehat{\alpha}($.$) exceeds \alpha_{I}$ and it is increasing in $R$ and $n_{0}$.

Proposition 6 says that the charity is less likely to outsource if it has a larger base of repeat donors and/or obtains a more generous grant. The reason is not that the marginal return of each dollar falls for the charity (as the production of the public good is linear in funds) but that with additional funds, each donor gives less, which makes it costlier for the charity to motivate the professional fundraiser. In fact, if, contrary to our assumption, 
the government grant were high enough so that $f(m+R) \leq R$, then donors would give nothing and outsourcing would trivially be suboptimal. Combining with the previous extension, Proposition 6 suggests that the charity is less likely to outsource its solicitations for an established program with a repeat donor base but the same charity can also afford to invest aggressively into establishing a new program.

\subsection{Heterogenous donors}

Up to now, we have also maintained that donors are identical. Besides facilitating the analysis, this assumption appears reasonable for settings where the charity has sufficient information about donors to divide them into homogenous groups that can be assigned to different fundraisers. Here, we consider the setting where the charity lacks such information and aims to motivate the professional for solicitations among heterogenous donors.

Let $N_{\tau}$ and $n_{\tau}$ denote the size of group $\tau$ and the number of solicitations by the professional from that group where $\tau=1, \ldots, k$. Without loss of generality, let equilibrium gifts be ordered such that $g_{1} \geq g_{2} \geq \ldots \geq g_{k}$. It is intuitive that the professional will follow this ascending order. If he stops soliciting with group $\tau$, then the charity retains

$$
\bar{G}_{\tau}=(1-s)\left(\sum_{j=1}^{\tau-1} N_{j} g_{j}+n_{\tau} g_{\tau}\right) .
$$

Modifying (4), the optimal $n_{\tau}$ is determined by:

$$
\sum_{j=1}^{\tau-1} N_{j}+n_{\tau}=\left(s g_{\tau}\right)^{\alpha_{o}} .
$$

Inserting (13) into (12), the percentage $s_{\tau}$ maximizes

$$
\bar{G}_{\tau}=(1-s)\left(\sum_{j=1}^{\tau-1} N_{j}\left(g_{j}-g_{\tau}\right)+\left(s g_{\tau}\right)^{\alpha_{o}} g_{\tau}\right) .
$$

Note that for a homogenous population, namely $g_{j}=g$, we have $s_{\tau}=\frac{\alpha_{o}}{1+\alpha_{o}}$ as in (6). In general, $s_{\tau}$ is decreasing in $\tau$. Due to rising marginal cost and diminishing donations, the professional is provided with fewer incentives to solicit from one more group. ${ }^{30}$ Hence, we predict that the charity whose donor base is more heterogenous is expected to offer a lower percentage to the fundraiser.

\footnotetext{
${ }^{30}$ In order for the professional to stop soliciting with group $\tau$, his FOC must satisfy $s_{\tau} g_{\tau+1}-\left(\sum_{j=1}^{\tau} N_{j}\right)^{\frac{1}{\alpha_{0}}}<$ 0 ; in turn, the FOC for (14) must satisfy $\left.\frac{d}{d s} \bar{G}_{\tau}\right|_{s=\left(\sum_{j=1}^{\tau} N_{j}\right)^{\frac{1}{\alpha_{0}}} / g_{\tau+1}}<0$. Simplifying the latter condition we find $g_{\tau+1}^{2}<\left(\sum_{j=1}^{\tau} N_{j}\right)^{\frac{1}{\alpha_{0}}}\left(g_{\tau+1}+\frac{\sum_{j=1}^{\tau} N_{j} g_{j}}{\alpha_{o} \sum_{j=1}^{\tau} N_{j}}\right)$.
} 


\subsection{Percentage vs. per-call contracts}

Besides a percentage contract, another commonly used contract in professional fundraising is per-call based under which the professional is paid a fixed amount $c>0$ per solicitation. Note that a per-call contract insures the fundraiser against loses whereas a percentage contract insures the charity. This difference would, however, matter only if (1) donations admit exogenous uncertainty so loses are possible in equilibrium and (2) at least one party is risk averse. The former requirement is not satisfied in our base model: following the standard models of giving (Bergstrom et al. 1986; Andreoni 1989), donations are perfectly predictable in equilibrium. To this end, suppose that individuals are pure warm-glow givers and from the charity and fundraiser's perspective, their gifts are uncertain; perhaps the fundraiser has limited information about donors' preferences and/or incomes. For convenience, suppose that individual gift $g_{i}$ is an independent draw from a normal distribution, $N\left(\mu, \sigma^{2}\right)$, and when risk-averse, the charity and fundraiser possess CARA utilities. $^{31}$

Proposition 7 (a) With risk-averse charity and risk-neutral fundraiser, both parties are better off under percentage based contract; $(\boldsymbol{b})$ with risk-neutral charity and risk-averse fundraiser, both parties are better off under per-call based contract; and (c) With risk-neutral charity and riskneutral fundraiser, percentage and per-call based contracts are payoff equivalent;

The intuition behind Proposition 7 is familiar from principal-agent problems: a contract performs better than another to the extent that it allocates risk toward the party who can tolerate it. This is achieved by a percentage contract in part (a) since the charity is the riskaverse party, and by a per-call contract in part (b) since the fundraiser is the risk-averse. By the same logic, the equivalence is obtained in part (c).

\section{Discussion and conclusion}

Despite being generous, few people give without being solicited. Charities often turn to high-priced professional solicitors, claiming to be unequipped for running large-scale fundraising campaigns. Professional solicitors explain their expensive services by the onerous task of prospecting and retaining donors. State attorneys general, however, ar-

\footnotetext{
${ }^{31}$ The CARA-Normal setting is widely used in agency problems.
} 
gue that donors are uninformed about the high costs of paid solicitations and would give little otherwise.

To rationalize these viewpoints, we have proposed a model of outsourced fundraising in which the charity optimally retains a professional solicitor who is significantly more efficient in fundraising and motivates him by offering a high percentage of the gross receipts. This implies that donors who are merely informed of paid solicitations would anticipate a high price of giving and become much less generous, rendering this practice unprofitable for the charity. The charity is found to benefit from professional solicitors if: (1) donors are uninformed; (2) donors are purely warm-glow givers; or (3) the charity worries primarily about its watchdog rating.

One interpretation of our results is that transparency about fundraising methods is irrelevant or even undesirable because both the charity and the donors ultimately prefer greater net funds raised. An alternative interpretation, however, is that such transparency is important to keep the high public confidence in the charitable sector. Intuitively, additional funds received from uninformed donors in the short term may well be outweighed by the reduced giving due to damaged reputation. While this intuition can only be formalized within a fully dynamic model, efforts by state attorneys to inform donors about professional solicitations point to such reputational concerns. In this sense, the existing disclosure laws that require paid solicitors to reveal themselves to donors also appears well-founded. The weakness of these laws may, however, be in their enforcement since communications between the solicitor and donors seem hard to verify. In fact, even if they are verified, it is the exclusive power of the attorney general to sue charities and their fiduciaries. ${ }^{32}$ Given this, we believe that attorneys general can better serve donors by raising awareness about professional solicitations than by publishing detailed reports that few donors might read. That is, simply educating the public to inquire whether solicitors are paid or not may suffice to regulate the market for professional fundraising. ${ }^{33}$ Our results also suggest that if people give purely for self-interest or warm-glow, then charities should explore more cost-effective ways of fundraising to increase their warm-glow. For instance, Castillo et al. (2014) report that the advent of social media offers a promising peer-to-peer fundraising platform.

\footnotetext{
${ }^{32}$ In particular, members of the general public are precluded from suing charitable fiduciaries or bring suit to force an attorney general to sue a charity or its fiduciaries; see Hopkins (2009).

${ }^{33}$ If asked, fundraisers need to truthfully identify themselves.
} 
In conclusion, our paper is a first attempt to address the "boundaries" of a nonprofit organization: when charitable activities are undertaken in-house or outsourced. Future work should open the organizational "black-box" of a nonprofit itself so its key decisions on services and fundraising are better understood. 


\section{A Appendix}

Proof of Proposition 1. To ease notation, we drop the superscript " $I$ " in this proof. Note first that in equilibrium, $n>0$ if and only if $\bar{G}>0$, or equivalently $G-C>0$. Clearly, if $G-C>0$, it must follow that $n>0$ to have $G>0$. Now suppose $n>0$ but $G-C \leq 0$. Then, by definition no public good would be provided, i.e., $\bar{G}=0$. In particular, a solicited donor would be strictly better off contributing nothing to the public good. Given this, the charity would find it optimal not to solicit any donor, contradicting $n>0$.

Next consider a solicited donor's problem. Conjecturing $n$, its $\operatorname{cost} C$, and others' total contribution $G_{-i}$, donor $i$ solves

$$
\begin{aligned}
& \max _{x_{i}, g_{i}} u\left(x_{i}, G-C\right) \\
& \text { s. to } x_{i}+g_{i}=m .
\end{aligned}
$$

By definition, $g_{i}=(G-C)-\left(G_{-i}-C\right)$, or equivalently $g_{i}=\bar{G}-\bar{G}_{-i}$ where $\bar{G} \equiv G-C$ and $\bar{G}_{-i} \equiv G_{-i}-C$. Thus, $i^{\prime}$ s program can be written:

$$
\begin{gathered}
\max _{x_{i}, \bar{G}} u\left(x_{i}, \bar{G}\right) \\
\text { s. to } x_{i}+\bar{G}=m+\bar{G}_{-i} \\
\bar{G} \geq \bar{G}_{-i}
\end{gathered}
$$

Following Bergstrom et al.'s (1986) original treatment, let $\bar{G}=\max \left\{f\left(m+\bar{G}_{-i}, 1\right), \bar{G}_{-i}\right\}$ be the solution to this program, where, as defined in the text, $f$ is the (Marshallian) demand for the public good whose relative price is clearly 1 from $i$ 's budget constraint. In equilibrium, individual contributions must be equal. To prove, suppose this is not the case. Then, we would have $g_{k}>g_{l}$ for some donors $k$ and $l$, which would mean $g_{k}>0$ and thus $\bar{G}=f\left(m+\bar{G}_{-k}\right)$. It would also mean that $\bar{G} \geq f\left(m+\bar{G}_{-l}\right)$. Together we must have $f\left(m+\bar{G}_{-k}\right) \geq f\left(m+\bar{G}_{-l}\right)$ or equivalently $g_{k} \leq g_{l}$, yielding a contradiction. Hence, in a fundraising equilibrium, $g_{i}=g$ for all solicited donors. Moreover, $G-C>0$ as argued above, it must be that $g>\frac{C}{n}>0$, which implies $\bar{G}=f\left(m+\bar{G}_{-i}\right)$ or equivalently

$$
\bar{G}=f(m+\bar{G}-g) .
$$

On the charity side, Eqs. (2) and (1) reveal that

$$
G=(1+1 / \alpha) C \text { and } \bar{G}=C / \alpha .
$$


Together with the facts that $n=[(1+1 / \alpha) C]^{\frac{\alpha}{1+\alpha}}$ from Eq.(1) and $g=\frac{G}{n}$ by symmetry, Eqs.(A-1) and (A-2) thus require that

$$
\begin{aligned}
C / \alpha & =f\left(m+C / \alpha-\frac{(1+1 / \alpha) C}{[(1+1 / \alpha) C]^{\frac{\alpha}{1+\alpha}}}\right) \\
& =f\left(m+C / \alpha-(1+1 / \alpha)^{\frac{1}{1+\alpha}} C^{\frac{1}{1+\alpha}}\right)
\end{aligned}
$$

Define

$$
\Phi(C)=C / \alpha-f\left(m+C / \alpha-(1+1 / \alpha)^{\frac{1}{1+\alpha}} C^{\frac{1}{1+\alpha}}\right) .
$$

Evidently, $\Phi(0)=-f(m)<0$ and $\Phi\left(\frac{m^{1+\alpha}}{1+1 / \alpha}\right)=\frac{m^{1+\alpha}}{1+\alpha}-f\left(\frac{m^{1+\alpha}}{1+\alpha}\right)>0$. Thus, there is a solution to $\Phi(C)=0$ such that $C \in\left(0, \frac{m^{1+\alpha}}{1+1 / \alpha}\right)$. Moreover, since $\Phi^{\prime}(C)=\frac{1}{\alpha}\left[1-f^{\prime}() \times.(1-\right.$ $1 / n)]>0$, the solution is unique, proving the existence of a unique fundraising equilibrium.

To prove comparative statics with respect to $\alpha$, first differentiate (A-1):

$$
\bar{G}^{\prime}=f_{m} \times\left(\bar{G}^{\prime}-g^{\prime}\right),
$$

which implies that $\left(1-f_{m}\right) \times \bar{G}^{\prime}=-f_{m} \times g^{\prime}$. Since $0<f_{m}<1$,

$$
\bar{G}^{\prime}={ }^{s i g n}-g^{\prime} .
$$

Next, since $\bar{G}=\frac{C}{\alpha}$ from Eq.(A-2) and $g=n^{\frac{1}{\alpha}}$ from Eq.(2), using Eq.(1), we respectively write: $\ln (\bar{G})=-\ln (1+\alpha)+\left(1+\frac{1}{\alpha}\right) \ln n$ and $\ln g=\frac{1}{\alpha} \ln n$. Differentiating both with respect to $\alpha$ yields,

$$
\begin{aligned}
\frac{\bar{G}^{\prime}}{\bar{G}} & =-\frac{1}{1+\alpha}-\frac{\ln n}{\alpha^{2}}+\left(1+\frac{1}{\alpha}\right) \frac{n^{\prime}}{n} \\
\frac{g^{\prime}}{g} & =-\frac{\ln n}{\alpha^{2}}+\frac{1}{\alpha} \frac{n^{\prime}}{n}
\end{aligned}
$$

Suppose $g^{\prime} \geq 0$. Then, $\bar{G}^{\prime} \leq 0$ by Eq.(A-3), which, from Eq.(A-4), implies that $-\frac{1}{1+\alpha}+$ $\frac{n^{\prime}}{n} \leq 0$. Moreover, since $g^{\prime} \geq 0$ by hypothesis, $-\frac{\ln n}{\alpha^{2}}+\frac{1}{\alpha} \frac{n^{\prime}}{n} \geq 0$ by Eq.(A-5). Together we have

$$
\frac{\ln n}{\alpha} \leq \frac{n^{\prime}}{n} \leq \frac{1}{1+\alpha}
$$

which requires that $n \leq e^{\frac{\alpha}{1+\alpha}}$, contradicting our assumption that $n>e^{\frac{\alpha}{1+\alpha}}$. Hence, $g^{\prime}<0$ and in turn $\bar{G}^{\prime}>0$ and $n^{\prime}>0$. Furthermore, the fact that $\bar{G}^{\prime}>0$ implies from Eq.(A-2) that $C^{\prime}>0$ and $G^{\prime}>0$. 
Proof of Proposition 2. To ease notation, we drop the superscript " $o$ " in this proof. Conjecturing $n, s$ and $G_{-i}$, donor $i$ solves

$$
\begin{gathered}
\max _{x_{i}, g_{i}} u\left(x_{i},(1-s) G\right) \\
\text { s. to } x_{i}+g_{i}=m .
\end{gathered}
$$

By definition, $g_{i}=G-G_{-i}=\frac{1-s}{1-s} G-\frac{1-s}{1-s} G_{-i}$. Defining $p=\frac{1}{1-s}, g_{i}=p \bar{G}-p \bar{G}_{-i}$ where $\bar{G} \equiv(1-s) G$ and $\bar{G}_{-i} \equiv(1-s) G_{-i}$. Thus, $i$ 's program can be written:

$$
\begin{gathered}
\max _{x_{i}, \bar{G}} U\left(x_{i}, \bar{G}\right) \\
\text { s. to } x_{i}+p \bar{G}=m+p \bar{G}_{-i} \\
\bar{G} \geq \bar{G}_{-i} .
\end{gathered}
$$

The solution to this program is $\bar{G}=\max \left\{f\left(m+p \bar{G}_{-i} ; p\right), \bar{G}_{-i}\right\}$ where $f(m, p)$ is the demand for the public good. As in the previous proof, it is straightforward to argue that in equilibrium, gifts must be symmetric and positive. Hence, in equilibrium

$$
\bar{G}=f(m+p \bar{G}-g ; p)
$$

On the charity side, from Eqs. (4) and (6), it must be that

$$
G=\left(1+\frac{1}{\alpha}\right)^{2} C \text { and } \bar{G}=\left(1+\frac{1}{\alpha}\right) \frac{1}{\alpha} C .
$$

Together with the fact that $n=\left[\left(1+\frac{1}{\alpha}\right) C\right]^{\frac{\alpha}{1+\alpha}}$ from Eq.(1) and $g=\frac{G}{n}$ by symmetry, Eqs.(A6) and (A-7) thus require that

$$
\begin{aligned}
\left(1+\frac{1}{\alpha}\right) \frac{C}{\alpha} & =f\left(m+\left(1+\frac{1}{\alpha}\right)^{2} C-\frac{\left(1+\frac{1}{\alpha}\right)^{2} C}{\left[\left(1+\frac{1}{\alpha}\right) C\right]^{\frac{\alpha}{1+\alpha}}} ; p\right) \\
& =f\left(m+\left(1+\frac{1}{\alpha}\right)^{2} C-\left(1+\frac{1}{\alpha}\right)^{\frac{2+\alpha}{1+\alpha}} C^{\frac{1}{1+\alpha}} ; p\right)
\end{aligned}
$$

Define

$$
\Psi(C)=\left(1+\frac{1}{\alpha}\right) \frac{C}{\alpha}-f\left(m+\left(1+\frac{1}{\alpha}\right)^{2} C-\left(1+\frac{1}{\alpha}\right)^{\frac{2+\alpha}{1+\alpha}} C^{\frac{1}{1+\alpha}} ; p\right) .
$$

Clearly, $\Psi(0)=-f(m ; p)<0$ and $\Psi\left(\frac{m^{1+\alpha}}{\left(1+\frac{1}{\alpha}\right)^{2+\alpha}}\right)=\frac{1}{1+\alpha}\left[\frac{m^{1+\alpha}}{\left(1+\frac{1}{\alpha}\right)^{\alpha}}-(1+\alpha) f\left(\frac{m^{1+\alpha}}{\left(1+\frac{1}{\alpha}\right)^{\alpha}} ; p\right)\right]>0$. The latter follows because $p=1+\alpha$ and $M-p f(M ; p)>0$ from the budget line. Thus, there is a solution to $\Psi(C)=0$ such that $C \in\left(0, m^{1+\alpha} /\left(1+\frac{1}{\alpha}\right)^{2+\alpha}\right)$. Moreover, since $p f_{m}<1$ and $f_{m}>0, \Psi^{\prime}(C)=\left(1+\frac{1}{\alpha}\right) \frac{1}{\alpha}\left[1-p f_{m}+\frac{f_{m}}{n}\right]>0$, the solution is unique, which 
proves the existence of a unique fundraising equilibrium.

Differentiating (A-6) with respect to $\alpha$ and recalling that $p=1+\alpha$,

$$
\bar{G}^{\prime}=f_{m} \times\left(p^{\prime} \bar{G}+p \bar{G}^{\prime}-g^{\prime}\right)+f_{p} p^{\prime},
$$

or since $p=1+\alpha, \bar{G}=f$ and $\varepsilon^{p}=\frac{p f_{p}}{f}$,

$$
\left(1-p f_{m}\right) \bar{G}^{\prime}=\frac{\bar{G}}{p}\left(p f_{m}-\left|\varepsilon^{p}\right|\right)-f_{m} g^{\prime} .
$$

Next, since $\bar{G}=\left(1+\frac{1}{\alpha}\right) \frac{C}{\alpha}=\frac{n^{1+\frac{1}{\alpha}}}{\alpha}$ and $s g=n^{\frac{1}{\alpha}}$, we have $\ln \bar{G}=-\ln \alpha+\left(1+\frac{1}{\alpha}\right) \ln n$ and $\ln g+\ln \left(\frac{\alpha}{1+\alpha}\right)=\frac{1}{\alpha} \ln n$. Thus

$$
\begin{aligned}
\frac{g^{\prime}}{g} & =-\frac{1}{\alpha(1+\alpha)}-\frac{1}{\alpha^{2}} \ln n+\frac{1}{\alpha} \frac{n^{\prime}}{n} \\
\frac{\bar{G}^{\prime}}{\bar{G}} & =-\frac{1}{\alpha}+\left(1+\frac{1}{\alpha}\right) \frac{n^{\prime}}{n}-\frac{1}{\alpha^{2}} \ln n
\end{aligned}
$$

From the above it follows that

$$
\frac{\bar{G}^{\prime}}{\bar{G}}=(1+\alpha) \frac{g^{\prime}}{g}+\frac{1}{\alpha} \ln n .
$$

Substituting for $g^{\prime}$ into (A-8), we obtain:

$$
\left(1-p f_{m}\right) \bar{G}^{\prime}=\frac{\bar{G}}{p}\left(p f_{m}-\left|\varepsilon^{p}\right|\right)-f_{m} \times\left(\frac{g \bar{G}^{\prime}}{p \bar{G}}-\frac{g \ln n}{\alpha(1+\alpha)}\right) .
$$

Given that $p \bar{G}=G$ and $\frac{G}{g}=n$, it follows that

$$
\begin{aligned}
\left(1-p f_{m}+\frac{f_{m}}{n}\right) \bar{G}^{\prime} & =\frac{\bar{G}}{p}\left(p f_{m}-\left|\varepsilon^{p}\right|\right)+f_{m} \frac{g \ln n}{\alpha p} \\
& =\frac{\bar{G}}{p}\left(p f_{m}-\left|\varepsilon^{p}\right|\right)+f_{m} \frac{G \ln n}{\alpha n p} \\
& =\frac{\bar{G}}{p}\left(p f_{m}-\left|\varepsilon^{p}\right|\right)+f_{m} \frac{\bar{G} \ln n}{\alpha n} \\
& =\frac{\bar{G}}{p}\left(p f_{m}-\left|\varepsilon^{p}\right|\right)+\frac{\bar{G}}{p} p f_{m} \frac{\ln n}{\alpha n} . \\
& =\frac{\bar{G}}{p}\left[p f_{m}\left(1+\frac{\ln n}{\alpha n}\right)-\left|\varepsilon^{p}\right|\right] .
\end{aligned}
$$

Since $p f_{m}<1$ and $f_{m}>0, \bar{G}^{\prime}>0$ if and only if $\left|\varepsilon^{p}\right|<p f_{m}\left(1+\frac{\ln n}{\alpha n}\right)$, as desired. 
Proof of Proposition 3. Suppose that the charity outsources but unlike in the base model, the fundraiser verifiably discloses $s$ to donors. Let $n(s)$ be the equilibrium number of solicitations and $\bar{g}(s) \equiv g(s, n(s))$. Given $s$, the fundraiser solves

$$
\Pi^{o}(s)=\max _{n}[n s \bar{g}(s)-C(n ; \alpha)] .
$$

The FOC for the fundraiser is: $s \bar{g}(s)=n^{\frac{1}{\alpha}}$. Setting $n=n(s)$ and differentiating with respect to $s$, we obtain

$$
\frac{1}{\alpha} \frac{n_{s}}{n}=\frac{1}{s}+\frac{d \bar{g}(s) / d s}{\bar{g}(s)} .
$$

On the donor side, recalling $p=1 /(1-s), \bar{G}=G / p$ and $G=n g$, we re-write Eq.(A-1):

$$
n(s) \bar{g}(s)=p f(m+(n(s)-1) \bar{g}(s) ; p) \text {. }
$$

Differentiating with respect to $s$ yields

$$
\left(1-p f_{m}\right) n_{s} \bar{g}(s)+\left(n-(n-1) p f_{m}\right) \times d \bar{g}(s) / d s=\frac{1}{(1-s)^{2}} f(.) \times\left(1-\left|\mathcal{E}^{p}\right|\right) .
$$

Finally, subject to $n=n(s)$, the charity's program reduces to:

$$
\max _{s} \bar{G}(s) \equiv(1-s) s^{\alpha}(\bar{g}(s))^{1+\alpha},
$$

which is equivalent to Eq.(5) except that $g^{o}$ is replaced with $\bar{g}(s)$.

$$
\text { FOC: } \frac{d \bar{G}(s) / d s}{\bar{G}(s)} \equiv-\frac{s(1+\alpha)-\alpha}{s(1-s)}+(1+\alpha) \frac{d \bar{g}(s) / d s}{\bar{g}(s)}=0,
$$

which, given $s^{o}=\frac{\alpha}{1+\alpha}$, results in:

$$
\frac{d \bar{g}(s) / d s}{\bar{g}(s)}=\frac{s-s^{o}}{s(1-s)}
$$

From here, we find the optimal disclosure contract, $s^{o, d}$. Eqs.(A-10) and (A-12) reveal that $n_{s}=\alpha n \frac{1-s^{o}}{s(1-s)}>0$. Since $p f_{m}<1$ by normality and $\left|\varepsilon^{p}\right| \geq 1$ by hypothesis, this implies that $d \bar{g}(s) / d s<0$ from Eq.(A-11) and thus $s^{o, d}<s^{o}$ from Eq.(A-12).

By the Envelope Theorem, note that $d \Pi^{0}(s) / d s>0$ if and only if $d(s \bar{g}(s)) / d s>0$. Note also that

$$
\begin{aligned}
d(s \bar{g}(s)) / d s & =\bar{g}(s)[1+s d \bar{g}(s) / d s] \\
& =\bar{g}(s) \frac{1-s^{o}}{1-s} \text { at } s=s^{o, d} \\
& >0 \text { at } s=s^{o, d}
\end{aligned}
$$


Thus, $d \Pi^{o}(s) / d s>0$ at $s=s^{o, d}$. Since $s^{o, d}<s^{o}$, this implies that $\Pi^{o}\left(s^{o, d}\right)<\Pi^{o}\left(s^{o}\right)$; that is, the fundraiser is worse off under disclosure than under nondisclosure. The charity is, however, better off under disclosure because it sets $s ; s=s^{o}$ is feasible and $s^{o, d} \neq s^{o}$.

Proof of Proposition 4. Fix $\alpha_{I}$ and let $g=g^{I}$. Then, $\bar{G}^{I}(\alpha, g)=\frac{1}{1+\alpha} g^{1+\alpha}$ and $\bar{G}^{o}(\alpha, g)=$ $\frac{1}{\alpha(1+1 / \alpha)^{1+\alpha}} g^{1+\alpha}$. It is straightforward to verify that $\bar{G}^{o}\left(\alpha_{I}, g\right)<\bar{G}^{I}\left(\alpha_{I}, g\right)$. Moreover, since $g>1+1 / \alpha_{0}$ from Eq.(4), $\bar{G}^{o}\left(\alpha_{0}, g\right)$ is strictly increasing in $\alpha_{0}$ and $\lim _{\alpha_{0} \rightarrow \infty} \bar{G}^{o}\left(\alpha_{0}, g\right)=\infty$. Hence, there is a unique and finite $\underline{\alpha}\left(g, \alpha_{I}\right)>\alpha_{I}$ such that

$$
\bar{G}^{I}\left(\alpha_{I}, g\right)=\bar{G}^{o}\left(\underline{\alpha}\left(g, \alpha_{I}\right), g\right)
$$

and $\bar{G}^{o}\left(\alpha_{0}, g\right)>\bar{G}^{I}\left(\alpha_{I}, g\right)$ for $\alpha_{o}>\underline{\alpha}\left(g, \alpha_{I}\right)$. Next differentiating both sides of Eq.(A-13), we obtain

$$
\frac{\partial \underline{\alpha}}{\partial g}=\operatorname{sign} \frac{\partial \bar{G}^{I}\left(\alpha_{I}, g\right)}{\partial g}-\frac{\partial \bar{G}^{o}(\underline{\alpha}, g)}{\partial g} .
$$

Note that $\frac{\partial \bar{G}^{I}\left(\alpha_{I, g}\right)}{\partial g}=\left(1+\alpha_{I}\right) \frac{\bar{G}^{I}\left(\alpha_{I, g}\right)}{g}$ and $\frac{\partial \bar{G}^{o}(\underline{\alpha}, g)}{\partial g}=(1+\underline{\alpha}) \frac{\bar{G}^{o}(\underline{\alpha}, g)}{g}$. Together with the facts that $\bar{G}^{o}(\underline{\alpha}, g)=\bar{G}^{I}\left(\alpha_{I}, g\right)$ and $\underline{\alpha}>\alpha_{I}$, we have

$$
\frac{\partial \underline{\alpha}}{\partial g}={ }^{\operatorname{sign}}\left(\alpha_{I}-\underline{\alpha}\right) \frac{\bar{G}^{I}\left(\alpha_{I}, g\right)}{g}<0,
$$

proving the first comparative static. To prove the one with respect to $\alpha_{I}$, we again differentiate both sides of Eq.(A-13) by recalling that $g=g^{I}$ :

$$
\frac{\partial \underline{\alpha}}{\partial \alpha_{I}}=\frac{\frac{d \bar{G}^{I}}{d \alpha_{I}}-\frac{\partial \bar{G}^{o}\left(\alpha_{o}, g^{I}\right)}{\partial g} \times \frac{\partial g^{I}}{\partial \alpha_{I}}}{\frac{\partial \bar{G}^{o}\left(\alpha_{o}, g^{I}\right)}{\partial \alpha_{o}}}>0,
$$

because $\frac{d \bar{G}^{I}}{d \alpha_{I}}>0$ and $\frac{\partial g^{I}}{\partial \alpha_{I}}<0$ by Proposition 1 and $\frac{\partial \bar{G}^{0}\left(\alpha_{0}, g^{I}\right)}{\partial g}>0$ and $\frac{\partial \bar{G}^{0}\left(\alpha_{0}, g^{I}\right)}{\partial \alpha_{0}}>0$ follow from above.

Proof of Proposition 5. Using a similar argument to the proof of Proposition 1, it is easily argued that a unique equilibrium exists and equilibrium gifts must be symmetric and positive. Hence, on the donor side, the equilibrium condition reduces to:

$$
\bar{G}=\bar{f}\left(m+p \bar{G}-g ; \bar{G}-\frac{g}{p} ; p\right),
$$

where $\bar{G}_{-i}=\bar{G}-\bar{g}=\bar{G}-\frac{g}{p}$. Differentiating (A-14) with respect to $\alpha$ :

$$
\bar{G}^{\prime}=\bar{f}_{m} \times\left(p^{\prime} \bar{G}+p \bar{G}^{\prime}-g^{\prime}\right)+\bar{f}_{w} \times\left[\bar{G}^{\prime}-\frac{\left(p g^{\prime}-p^{\prime} g\right)}{p^{2}}\right]+\bar{f}_{p} p^{\prime}
$$


Recalling that $p=1+\alpha$ and $\bar{G}=\bar{f}$ from (A-14), it follows that:

$$
\left(1-p \bar{f}_{m}-\bar{f}_{w}\right) \bar{G}^{\prime}=\frac{\bar{G}}{p}\left(p \bar{f}_{m}-\left|\bar{\varepsilon}^{p}\right|\right)-\frac{1}{p}\left[\left(p \bar{f}_{m}+\bar{f}_{w}\right) g^{\prime}-\frac{\bar{f}_{w} n g}{n p}\right],
$$

where $\bar{\varepsilon}^{p}=\frac{p \bar{f}_{p}}{\bar{f}}$. Using Eq.(A-9) from the proof of Proposition 2, we know that: $\frac{g^{\prime}}{g}=$ $\frac{1}{1+\alpha} \frac{\bar{G}^{\prime}}{\bar{G}}-\frac{1}{\alpha} \frac{\ln n}{(1+\alpha)}$. Hence upon substituting for $g^{\prime}$,

$\left(1-p \bar{f}_{m}-\bar{f}_{w}\right) \bar{G}^{\prime}=\frac{\bar{G}}{p}\left(p \bar{f}_{m}-\left|\bar{\varepsilon}^{p}\right|\right)-\frac{1}{p}\left[\left(\frac{1}{(1+\alpha)} \frac{\bar{G}^{\prime} g}{\bar{G}}-\frac{1}{\alpha} \frac{(\ln n) n g}{(1+\alpha) n}\right)\left(p \bar{f}_{m}+\bar{f}_{w}\right)-\frac{\bar{f}_{w} n g}{n p}\right]$.

Since $p \bar{G}=G$ and $\frac{G}{g}=n$, we have

$$
\left(1-p \bar{f}_{m}-\bar{f}_{w}\right) \bar{G}^{\prime}=\frac{\bar{G}}{p}\left(p \bar{f}_{m}-\left|\bar{\varepsilon}^{p}\right|\right)-\frac{1}{p}\left[\left(\frac{\bar{G}^{\prime}}{n}-\frac{\ln n}{\alpha n} \bar{G}\right)\left(p \bar{f}_{m}+\bar{f}_{w}\right)-\frac{\bar{f}_{w} \bar{G}}{n}\right] .
$$

Furthermore,

$$
\begin{aligned}
{\left[1-\left(p \bar{f}_{m}+\bar{f}_{w}\right)+\frac{1}{n p}\left(p \bar{f}_{m}+\bar{f}_{w}\right)\right] \bar{G}^{\prime} } & =\frac{\bar{G}}{p}\left[p \bar{f}_{m}+\frac{\ln n}{\alpha n}\left(p \bar{f}_{m}+\bar{f}_{w}\right)+\frac{\bar{f}_{w}}{n}-\left|\bar{\varepsilon}^{p}\right|\right] \\
& =\frac{\bar{G}}{p}\left[p \bar{f}_{m}\left(1+\frac{\ln n}{\alpha n}\right)+\bar{f}_{w}\left(\frac{1}{n}+\frac{\ln n}{\alpha n}\right)-\left|\bar{\varepsilon}^{p}\right|\right] .
\end{aligned}
$$

Since $0<p \bar{f}_{m}+\bar{f}_{w} \leq 1, \bar{G}^{\prime}>0$ if and only if $\left|\bar{\varepsilon}^{p}\right|<p \bar{f}_{m}\left(1+\frac{1}{\alpha} \frac{\ln n}{n}\right)+\bar{f}_{w}\left(\frac{1}{n}+\frac{1}{\alpha} \frac{\ln n}{n}\right)$, as claimed.

Proof of Proposition 6. Let $R \geq 0$ and $n_{0} \geq 0$ be the government grant and the number of repeat donors, respectively. As in the proof of Proposition 1, it is readily argued that given $n_{0}+n$, there is a unique equilibrium gift $g$, resulting in total contribution: $G=$ $\left(n_{0}+n\right) g$, and total net contribution: $\bar{G}=G-C$. In particular, in the presence of $R$, a modified Eq.(A-1) holds in equilibrium:

$$
\bar{G}+R=f(m+\bar{G}+R-g) .
$$

From the charity's optimization, we have $n=g^{\alpha}$, which, since $n=[(1+1 / \alpha) C]^{\frac{\alpha}{1+\alpha}}$ from Eq.(1), reveals that $g=[(1+1 / \alpha) C]^{\frac{1}{1+\alpha}}$,

$$
G=(1+1 / \alpha) C+n_{0}[(1+1 / \alpha) C]^{\frac{1}{1+\alpha}} \text { and } \bar{G}=C / \alpha+n_{0}[(1+1 / \alpha) C]^{\frac{1}{1+\alpha}} .
$$

Inserting these into Eq.(A-15), we obtain

$$
C / \alpha+n_{0}[(1+1 / \alpha) C]^{\frac{1}{1+\alpha}}+R=f\left(m+R+C / \alpha+\left(n_{0}-1\right)[(1+1 / \alpha) C]^{\frac{1}{1+\alpha}}\right) .
$$


Define

$\widehat{\Phi}\left(C ; n_{0}, R\right)=C / \alpha+n_{0}[(1+1 / \alpha) C]^{\frac{1}{1+\alpha}}+R-f\left(m+R+C / \alpha+\left(n_{0}-1\right)[(1+1 / \alpha) C]^{\frac{1}{1+\alpha}}\right)$.

Clearly, $\widehat{\Phi}\left(0 ; n_{0}, R\right)=R-f(m+R)<0$ by assumption and $\widehat{\Phi}\left(\frac{m^{1+\alpha}}{1+1 / \alpha} ; n_{0}, R\right)=\frac{m^{1+\alpha}}{1+\alpha}+$ $n_{0} m+R-f\left(\frac{m^{1+\alpha}}{1+\alpha}+n_{0} m+R\right)>0$ by normality. Thus, $\widehat{\Phi}\left(C^{*} ; n_{0}, R\right)=0$ for some $C^{*} \in$ $\left(0, \frac{m^{1+\alpha}}{1+1 / \alpha}\right)$. Moreover, since $\widehat{\Phi}_{C}\left(C ; n_{0}, R\right)=\frac{1}{\alpha}\left[1+\frac{n_{0}}{n}-f_{m}() \times.\left(1+\frac{n_{0}}{n}-\frac{1}{n}\right)\right]>0$, the solution $C^{*}$ is unique, proving the existence of a unique fundraising equilibrium in this extension.

The existence of a unique cutoff $\widehat{\alpha}\left(R, n_{0}\right)$ follows the same line of arguments as in Proposition 4. In light of Proposition 4, it also suffices to show for the rest of Proposition 6 that equilibrium $g$ is decreasing in $R$ and $n_{0}$. Note that

$$
\widehat{\Phi}_{n_{0}}(.)=[(1+1 / \alpha) C]^{\frac{1}{1+\alpha}}\left(1-f_{m}(.)\right)>0 \text { and } \widehat{\Phi}_{R}(.)=1-f_{m}(.)>0 .
$$

Hence, $C^{*}$ is decreasing in $n_{0}$ and $R$; and so does $g$ because $g=[(1+1 / \alpha) C]^{\frac{1}{1+\alpha}}$.

Proof of Proposition 7. Since the proofs of parts (b) and (c) are similar, we only prove part (a) here. Let $\widetilde{G}_{n}$ denote the total donations if $n$ donors are solicited. Then, by the normal assumption, $\widetilde{G}_{n} \sim N\left(n \mu, n \sigma^{2}\right)$. Under a percentage contract, the charity solves

$$
\begin{gathered}
\max _{s, n} E\left[-e^{-R_{c}(1-s) \widetilde{G}_{n}}\right] \\
\text { s.to } s E\left[\widetilde{G}_{n}\right]-C(n ; \alpha) \geq 0 \\
n \in \arg \max _{\widehat{n}} s E\left[\widetilde{G}_{\widehat{n}}\right]-C(\widehat{n} ; \alpha) .
\end{gathered}
$$

Note that as in the text, (A-16) satisfied trivially since it holds for $n=0$. From (A-17), we have $n=(s \mu)^{\alpha}$. Inserting this into the certainty equivalent for the charity, the program reduces to

$$
\Pi_{C}^{\%, *}=\max _{s}(1-s)(s \mu)^{\alpha}\left[\mu-(1-s) \frac{R_{c} \sigma^{2}}{2}\right] .
$$

It can be shown that $s^{*}>\frac{\alpha}{1+\alpha}$. On the other hand, under a per-call contract, the charity solves:

$$
\begin{gathered}
\max _{s, n} E\left[-e^{-R_{c}\left(\widetilde{G}_{n}-n c\right)}\right] \\
\text { s.to } n c-C(n ; \alpha) \geq 0 \\
n \in \arg \max _{\widehat{n}} \widehat{n} c-C(\widehat{n} ; \alpha)
\end{gathered}
$$


Since, from (A-19), $n=c^{\alpha}$, the charity's program reduces to

$$
\Pi_{C}^{c, *}=\max _{c} c^{\alpha}\left(\mu-c-\frac{R_{c} \sigma^{2}}{2}\right)
$$

The FOC reveals that $c^{*}=\frac{\alpha}{1+\alpha}\left(\mu-\frac{R_{c} \sigma^{2}}{2}\right)$. Using this, simple algebra shows

$$
\Pi_{C}^{\%, *} \geq \Pi_{C}^{\%}\left(s=\frac{\alpha}{1+\alpha}\right)>\Pi_{C}^{c, *} .
$$

Moreover, on the fundraiser side, we observe

$$
\Pi_{F}^{\%, *}>\Pi_{F}^{\%}\left(s=\frac{\alpha}{1+\alpha}\right)>\Pi_{F}^{c, *}
$$




\section{References}

[1] Andreoni, J. "Giving with impure altruism: applications to charity and Ricardian equivalence," Journal of Political Economy 1989: 1447-58.

[2] Andreoni, J. "Toward a Theory of Charitable Fund-raising," Journal of Political Economy 1998: 1186-1213.

[3] Andreoni, J. "Leadership Giving in Charitable Fundraising," Journal of Public Economic Theory 2006: 1-22.

[4] Andreoni, J., and J. Miller. "Giving according to GARP: An experimental test of the consistency of preferences for altruism." Econometrica 2002: 737-53.

[5] Andreoni, J. and A. Payne. “Do Government Grants to Private Charities Crowd Out Giving or Fund-raising?" American Economic Review 2003: 792-812.

[6] Andreoni, J. and A. Payne. "Is Crowding Out Due Entirely to Fundraising? Evidence from a Panel of Charities," Journal of Public Economics 2011: 334-43.

[7] Andreoni, J. and A. Payne. Charitable Giving. Handbook of Public Economics (2013). Eds. A. Auerbach, R. Chetty, M. Feldstein and E. Saez

[8] Andreoni, J., and J. M. Rao. "The power of asking: How communication affects selfishness, empathy, and altruism." Journal of Public Economics 2011: 513-20.

[9] Auten, G., H. Sieg, and C. Clotfelter. "Charitable giving, income, and taxes: an analysis of panel data." American Economic Review 2002: 371-82.

[10] Bakija, J. and B. T. Heim. "How Does Charitable Giving Respond to Incentives and Income? New Estimates from Panel Data." National Tax Journal 2011, 64(2), 615-50.

[11] Barbieri, S., and D. Malueg. "Increasing Fundraising Success by Decreasing Donors' Choice," Journal of Public Economic Theory 2014.

[12] Bergstrom, T. , Blume L., and Varian, H. "On the Private Provision of Public Goods," Journal of Public Economics 1986:25-49.

[13] Brown, A. L., J. Meer, and J. F. Williams. "Social Distance and Quality Ratings in Charity Choice," 2014: NBER Working Paper No. 20182 
[14] Castillo, M., R. Petrie, and C. Wardell. "Fundraising through online social networks: A field experiment on peer-to-peer solicitation." Journal of Public Economics 2014.

[15] Chetty, R., A. Looney, and K. Kroft. "Salience and Taxation: Theory and Evidence." American Economic Review 2009:1145-77.

[16] Clotfelter, C. Federal Tax Policy and Charitable Giving. University of Chicago Press, Chicago. 1985

[17] Cnaan, R. A., Jones, K., Dickin, A., \& Salomon, M. “Nonprofit watchdogs: Do they serve the average donor?" Nonprofit Management and Leadership 2011:381-97.

[18] Eckel, C., and P. Grossman. "Rebate versus matching: does how we subsidize charitable contributions matter?" Journal of Public Economics 2003: 681-701.

[19] Edelman Trust Barometer 2014, http://www.edelman.com/insights/intellectualproperty /2014-edelman-trust-barometer/

[20] Edwards, J., and J. List. "Toward an understanding of why suggestions work in charitable fundraising: theory and evidence from a natural field experiment." Journal of Public Economics 2014.

[21] Finkelstein, A. "E-ztax: Tax salience and tax rates." Quarterly Journal of Economics 2009:969-1010.

[22] Fisman, R., S. Kariv, and D. Markovits. "Individual preferences for giving." American Economic Review 2007: 1858-76.

[23] Fishman, Stephen, and Ronald J. Barrett. 2013. Nonprofit Fundraising Registration: The 50-State Guide. 2nd Edition, NOLO, Berkeley, CA

[24] Giving USA 2013, Giving USA Foundation.

[25] Glazer, A., and Konrad, K. "A Signaling Explanation for Charity," American Economic Review 1996:1019-28.

[26] Gordon, T., C. Knock, and D. Neely. "The role of rating agencies in the market for charitable contributions: An empirical test." Journal of Accounting and Public Policy 2009: 469-84. 
[27] Greenfield, J. 2002. Fundraising Fundamentals: A Guide to Annual Giving for Professionals and Volunteers, Second Edition. John Wiley and Sons: New York.

[28] Greenlee, J. S., and Gordon, T. P. "The Impact of Professional Solicitors on Fund-Raising in Charitable Organizations." Nonprofit and Voluntary Sector Quarterly 1998:277-99.

[29] Harbaugh, W. "The prestige motive for making charitable transfers." American Economic Review 1998: 277-82.

[30] Holmstrom, B. “Moral hazard and observability." Bell Journal of Economics 1979: 74-91.

[31] Hope Consulting Report 2011, Driving Dollars to the Highest Performing Nonprofits

[32] Hopkins, B. Fundraising Law Made Easy. John Wiley \& Sons 2009.

[33] Huck, S., and I. Rasul. "Matched fundraising: Evidence from a natural field experiment." Journal of Public Economics 2011: 351-62.

[34] Keating, E. K., L. M. Parsons, and A. A. Roberts. 2003. The cost-effectiveness of nonprofit telemarketing campaigns. New Directions for Philanthropic Fundraising 41: 79-94.

[35] Kelly, K. Effective Fund-Raising Management. Hillsdale, N.J.: Erlbaum, 1998.

[36] Karlan, D. "Why Ranking Charities by Administrative Expenses is a Bad Idea" at http:/ / freakonomics.com/2011/06/09

[37] Khanna, J., J. Posnett, and T. Sandler. "Charity donations in the UK: New evidence based on panel data." Journal of Public Economics 1995: 257-72.

[38] Krasteva, S., and H. Yildirim. "(Un)informed Charitable Giving," Journal of Public Economics 2013: 14-26.

[39] List, J. "The Market for Charitable Giving," Journal of Economic Perspectives 2011: 15780.

[40] Marx, L., and S. Matthews "Dynamic Voluntary Contribution to a Public Project," Review of Economic Studies 2000: 327-358.

[41] Meer, J. and Rosen, H. "The ABCs of charitable solicitation," Journal of Public Economics 2011: 363-71. 
[42] Morgan, J., "Financing Public Goods by Means of Lotteries," Review of Economic Studies 2000: 761-84.

[43] Name-Correa, A., and H. Yildirim. "A Theory of Charitable Fund-Raising with Costly Solicitations." American Economic Review 2013: 1091-1107.

[44] Okten, C., and B. Weisbrod. "Determinants of donations in private nonprofit markets." Journal of Public Economics 75.2 (2000): 255-272.

[45] O'Neill, M. "Public Confidence in Charitable Nonprofits," Nonprofit and Voluntary Sector Quarterly 2009 38: 237-69.

[46] Perroni, C., G. Pogrebna, S. Sandford, and S. Smith. "Are Donors Afraid of Charities' Core Costs? Scale Economies in Non-Profit Provision," CAGE Discussion Paper Number 201, September 2014.

[47] Randolph, W.C. (1995). "Dynamic income, progressive taxes, and the timing of charitable contributions," Journal of Political Economy 103: 709-738.

[48] Ribar, D. and M. Wilhelm "Altruistic and joy-of-giving motivations in charitable behavior," Journal of Political Economy 2002: 425-57.

[49] Romano, R. and H. Yildirim. "Why Charities Announce Donations: a Positive Perspective." Journal of Public Economics 2001: 423-47.

[50] Rose-Ackerman, S., "Charitable giving and 'excessive' fundraising," Quarterly Journal of Economics 1982: 193-212.

[51] Sandberg, H. "Where Do Your Pennies Go? Disclosing Commissions for Charitable Fundraising," International Journal of Not-for-Profit Law, 2006, 8(4).

[52] Small, D., G. Loewenstein, and P. Slovic. "Sympathy and callousness: The impact of deliberative thought on donations to identifiable and statistical victims." Organizational Behavior and Human Decision Processes 2007: 143-153.

[53] Steinberg, R. "Does government spending crowd out donations? Interpreting the evidence," Annals of Public and Cooperative Economics 1991: 591-617.

[54] Vesterlund, L. "The Informational Value of Sequential Fundraising," Journal of Public Economics 2003: 627- 57. 
[55] Yildirim, H. "Andreoni-McGuire Algorithm and the Limits of Warm-Glow Giving," Journal of Public Economics 2014: 101-7.

[56] Yoruk, B., "How responsive are charitable donors to requests to give?," Journal of Public Economics 2009: 1111-7.

[57] Yoruk, B. "Charity ratings," 2014. Journal of Economics and Management Strategy (Forthcoming) 